\title{
Heat transfer direction dependence of heat transfer coefficients in annuli
}

\author{
Francois P.A. Prinsloo, Jaco Dirker", Josua P. Meyer \\ Department of Mechanical and Aeronautical Engineering, University of Pretoria, Private bag X20, \\ Hatfield, Pretoria, 0028, South Africa \\ *Corresponding author:
}

Email address: jaco.dirker@up.ac.za

Phone: $+27(0) 124202465$

\begin{abstract}
In this experimental study the heat transfer phenomena in concentric annuli in tube-in-tube heat exchangers at different annular Reynolds numbers, annular diameter ratios, and inlet fluid temperatures using water were considered. Turbulent flow with Reynolds numbers ranging from 15000 to 45000 , based on the average bulk fluid temperature was tested at annular diameter ratios of $0.327,0.386,0.409$ and 0.483 with hydraulic diameters of 17.00, 22.98, 20.20 and $26.18 \mathrm{~mm}$ respectively. Both heated and cooled annuli were investigated by conducting tests at a range of inlet temperatures ranging from $10^{\circ} \mathrm{C}$ to $30^{\circ} \mathrm{C}$ for heating cases and $30^{\circ} \mathrm{C}$ to $50^{\circ} \mathrm{C}$ for cooling cases. Of special interest was the direct measurement of local wall temperatures on the heat transfer surface, which is often difficult to obtain and evasive in data-sets. Continuous verification and re-evaluation of temperatures measurements were performed via in-situ calibration. It is shown that inlet fluid temperature and the heat transfer direction play significant roles on the magnitude of the heat transfer coefficient. A new adjusted Colburn $j$-factor definition is presented to describe the heating and cooling cases.
\end{abstract}

KEY WORDS: Convection, Heat exchanger, Annuli, Nusselt number, Colburn $j$-factor

\section{Acknowledgements}

The funding obtained from the National Research Foundation (NRF), Eskom Tertiary Education Support Programme (TESP), University of Stellenbosch / University of Pretoria, South African National Energy Research Institute (SANERI) / South African National Energy Development Institute (SANEDI), Council for Scientific and Industrial Research (CSIR), Energy Efficiency and Demand Side Management (EEDSM) Hub and NAC is acknowledged and duly appreciated. 


\section{Nomenclature}$$
a
$$

Annular diameter ratio

$[-]$

$A_{s}$

Surface area

$\left[\mathrm{m}^{2}\right]$

$A_{o}$

Cross sectional area of annulus

$\left[\mathrm{m}^{2}\right]$

$C_{o}$

Outer tube correlation coefficient

$[-]$

Specific heat

$[\mathrm{J} / \mathrm{kgK}]$

Control Volume

$[-]$

Hydraulic diameter

[m]

Energy Balance

[\%]

Convective heat transfer coefficient

$\left[\mathrm{W} / \mathrm{m}^{2} \mathrm{~K}\right]$

Thermal conductivity

[W/mK]

Colburn $j$-factor

$[-]$

Adjusted Colburn $j$-factor

$[-]$

Factor to take into account the temperature dependence

$[-]$

of fluid properties

$L_{h x}$

Heat exchange length

[m]

$\dot{m}$

Mass flow rate

$[\mathrm{kg} / \mathrm{s}]$

Number of thermocouples

$[-]$

Nusselt number

Exponent

$[-]$

Exponent in $j$-factor calculation

$[-]$

Reynolds number exponent

$[-]$

Prandtl number

$[-]$

Heat transfer rate

[W]

Average heat transfer rate

[W]

Reynolds number

$[-]$

Modified Reynolds number

$[-]$

Temperature

$\left[{ }^{\circ} \mathrm{C}\right]$

Logarithmic mean temperature difference

$\left[{ }^{\circ} \mathrm{C}\right]$

Average temperature

$\left[{ }^{\circ} \mathrm{C}\right]$

Axial length along the heat exchanger

[m]

\section{Greek symbols}

$\mu$

$\rho$

$\emptyset$

Kinematic viscosity

Density

$\left[\mathrm{kg} / \mathrm{m}^{3}\right]$

Factor in Equation 


\section{Subscripts}

$\begin{array}{ll}1 \text { (one) } & \text { Inner tube outer wall } \\ \text { avg } & \text { Average } \\ b & \text { Bulk property } \\ D_{h} & \text { Based on hydraulic diameter } \\ i & \text { Inner tube } \\ i i & \text { Inner tube inlet } \\ i o & \text { Inner tube outlet } \\ j & \text { Index number } \\ \text { local } & \text { Local property } \\ o & \text { Annulus } \\ \text { oi } & \text { Annulus inlet } \\ \text { oo } & \text { Annulus outlet } \\ w & \text { Wall }\end{array}$

\section{Introduction}

Annular flow passages are commonly found in several heat exchange devices, such as tube-in-tube heat exchangers. This type flow passage has received significant attention from researchers, but unfortunately, large discrepancies still exist among the correlations used for the prediction of heat transfer coefficients and pressure drop. One of the first investigations into the effect of the direction of heat flux was done by Dittus and Boelter [3]. Swamee et al. [4] produced a modified Sieder and Tate correlation, which could be used to optimize tube-in-tube heat exchangers, by including a compensation for annular ratio. Lu and Wang [5] also investigated heat transfer characteristics of water in annular heat exchangers in both a horizontal and vertical configuration. 
Table 1 provides a collection of selected published correlations for determining the Nusselt number in annuli. The correlations were selected due to their dependency on annular diameter ratio and/or heat flux directions. One of the most recent published correlations for determining Nusselt numbers for fully developed turbulent annular flow is that of Gnielinski [1]. In order to develop this correlation, experimental data was used, including that of Dirker and Meyer [2], to extend a previous correlation to include the effects of the annular diameter ratio, as well as the effect of temperature dependent property variations. Dirker and Meyer [2] investigated the differences between eleven existing correlations and found differences of up to $20 \%$ between the available correlations and, as a result, continued to present their own correlation from experimental data they obtained. 
Table 1 Some correlations for determining the heat transfer in a smooth concentric annulus

\begin{tabular}{|c|c|c|c|c|}
\hline Author(s) & Correlation & $\begin{array}{l}\text { Diameter } \\
\text { ratio }(a)\end{array}$ & $\begin{array}{l}\text { Reynolds } \\
\text { number } \\
\text { range }\end{array}$ & Medium \\
\hline $\begin{array}{l}\text { Gnielinski } \\
\text { [1] }\end{array}$ & $\begin{array}{l}\mathrm{Nu}_{D h}=\frac{(f / 8) \mathrm{Re}_{D h} \operatorname{Pr}_{o}}{\varphi+12.7 \sqrt{(f / 8)}\left(\operatorname{Pr}_{o}^{2 / 3}-1\right)}[1 \\
\left.+\left(\frac{D_{h}}{L_{h x}}\right)^{2 / 3}\right] F_{a n n} K \\
\varphi=1.07+\frac{900}{\operatorname{Re}_{D h}}-\frac{0.63}{\left(1+10 \operatorname{Pr}_{o}\right)} \\
K=\left(\frac{\operatorname{Pr}_{o}}{\operatorname{Pr}_{i w}}\right)^{0.11} \text { for liquids } \\
K=\left(\frac{T_{b}}{T_{i w}}\right)^{n} \text { for gasses with } n=0 \text { for cooling } \\
n=0.45 \text { for } 0.5<\frac{\mathrm{T}_{\mathrm{b}}}{\mathrm{T}_{\mathrm{iw}}}<1.0 \\
\mathrm{~F}_{\text {ann }}=0.75 \mathrm{a}^{-0.17} \\
f=\left(1.8 \log _{10} \operatorname{Re}^{*}-1.5\right)^{-2} \\
\operatorname{Re}^{*}=\operatorname{Re}_{\frac{\left(1+a^{2}\right) \ln a+\left(1-a^{2}\right)}{(1-a)^{2} \ln a}}^{(1-10}\end{array}$ & $\begin{array}{l}\text { Not } \\
\text { specified }\end{array}$ & $\begin{array}{l}\text { Not } \\
\text { specified }\end{array}$ & $\begin{array}{l}\text { All } \\
\text { mediums }\end{array}$ \\
\hline $\begin{array}{l}\text { Dirker \& } \\
\text { Meyer [2] }\end{array}$ & $\begin{array}{l}\mathrm{Nu}_{D h}=C_{o} \operatorname{Re}_{D h}^{P} \operatorname{Pr}^{\frac{1}{3}}\left(\frac{\mu_{o}}{\mu_{i w}}\right)^{0.14} \\
P=1.013 e^{-0.067 / a} \\
C_{o}=\frac{0.003 a^{1.86}}{0.063 a^{-3}-0.0674 a^{-2}+2.225 / a-1.157}\end{array}$ & $\begin{array}{l}0.3125- \\
0.588\end{array}$ & $\begin{array}{l}4 \times 10^{3} \\
3 \times 10^{4}\end{array}$ & Water \\
\hline $\begin{array}{l}\text { Dittus \& } \\
\text { Boelter [3] }\end{array}$ & $\begin{array}{l}\mathrm{Nu}_{D h}=0.023 \mathrm{Re}_{D h}{ }^{0.8} \mathrm{Pr}^{n} \\
\text { where } n=0.3 \text { (Cooling), } n=0.4 \text { (Heating) }\end{array}$ & $\begin{array}{l}\text { Not } \\
\text { specified }\end{array}$ & $>10^{4}$ & $\begin{array}{l}\text { Not } \\
\text { specified }\end{array}$ \\
\hline $\begin{array}{l}\text { Swamee et } \\
\text { al [4] }\end{array}$ & $\mathrm{Nu}_{D h}=\frac{0.027}{(1+1 / a)^{0.2}} \operatorname{Re}_{D h}{ }^{0.8} \operatorname{Pr}_{o}{ }^{1 / 3}\left(\frac{\mu_{o}}{\mu_{i w}}\right)^{0.14}$ & $\begin{array}{l}\text { Not } \\
\text { specified }\end{array}$ & $\begin{array}{l}\text { Not } \\
\text { specified }\end{array}$ & $\begin{array}{l}\text { Not } \\
\text { specified }\end{array}$ \\
\hline $\begin{array}{l}\text { Lu \& } \\
\text { Wang [5] }\end{array}$ & $\mathrm{Nu}_{D h}=0.0022 \mathrm{Re}_{D h}{ }^{0.8} \operatorname{Pr}_{o}^{0.4}$ & 0.6911 & $>3 \times 10^{3}$ & Water \\
\hline
\end{tabular}

It seems there is uncertainty as to whether a single correlation exists that can be used to accurately predict the heat transfer rate for annular flow at any combination of heat exchanger dimensions and fluid conditions. Additionally, there are opposing opinions regarding whether the effects of the direction of heat flux based on the fact that some correlations take this into account and other do not. 
The role of the annular diameter ratio (defined as the ratio of the inner wall diameter to the outer wall diameter of the annulus) is also not certain. These discrepancies have necessitated additional investigation to be conducted in order to attempt to address some of the disagreement and to remedy some of the shortfalls of existing experimental data-sets.

The purpose of this experimental study was to obtain experimental data with relatively low uncertainties in order to validate existing correlations and to identify the core aspects that influence the heat transfer characteristics during turbulent flow in annular flow passages that have neither uniform wall temperatures nor uniform wall heat fluxes. Special attention was given to the direct measurement of the inner wall temperatures of the annular flow passage. Due to the difficulty associated with this, investigators often do not measure local wall temperatures, even though it is required in several correlations to evaluate the fluid properties at the heat transfer surface. Temperature measurements were taken at different fluid velocities, annular diameter ratios, and inlet temperature of water. For this a large set of data was gathered for both heated and cooled annuli covering annular ratios ranging from 0.327 to 0.483 , Reynolds numbers ranging from 15000 to 45000 and water inlet temperatures ranging from $10^{\circ} \mathrm{C}$ to $30^{\circ} \mathrm{C}$ for heating cases and $30^{\circ} \mathrm{C}$ to $50^{\circ} \mathrm{C}$ for cooling cases. The findings in this article is intended to improve the understanding of the annular heat transfer phenomenon.

\section{Experimental Setup}

The experimental setup was designed as a closed loop system consisting of a test bench capable of operating with different interchangeable test sections (tube-in-tube heat exchangers).

\subsection{Experimental Facility}

Fig. 1 gives the layout of the experimental facility. The test bench consisted of a hot water loop and a cold water loop. The hot water loop (shown in red) was serviced by a $36 \mathrm{~kW}$ electric heater in a reservoir with a capacity of 1000 litres (item 1a) which was thermostatically regulated the water within $\pm 1^{\circ} \mathrm{C}$ of the selected temperature. The water was pumped through the loop with either one of two positive displacement pumps (items 3 a \& $3 b$ ) with maximum flow rates of $2.8 \mathrm{~m}^{3} / \mathrm{h}$ and $14 \mathrm{~m}^{3} / \mathrm{h}$. Each pump's speed was controlled with a variable speed drive. The pumps were connected to accumulators to dampen out the pulsations in the flow (item $5 \mathrm{a}$ had a volume of $0.006 \mathrm{~m}^{3}$ and item $5 \mathrm{~b}$ had a volume of $0.032 \mathrm{~m}^{3}$ ). Mass flow rates were measured with Coriolis flow meters with effective ranges of $0-0.607 \mathrm{~kg} / \mathrm{s}$ (item $8 \mathrm{a}$ ) and $0.694-5.55 \mathrm{~kg} / \mathrm{s}$ (item $8 \mathrm{~b}$ ), and associated accuracies of $0.1 \%$ of their full scale. A filter was installed to prevent the circulation of loose particles. The loop was equipped with pressure relief valves to protect against pressure surges. Non-return valves were used to protect the pumps. Numerous pressure dial gauges were installed throughout the loop, to assist with 
in-time pressure monitoring. Valves (item $2 \mathrm{~b} \& 2 \mathrm{c}$ ) allowed the user to either pump through the test section (item 11), or through the bypass line back to the reservoir. During experimental runs the bypass line was fully closed to insure correct mass flow measurement.
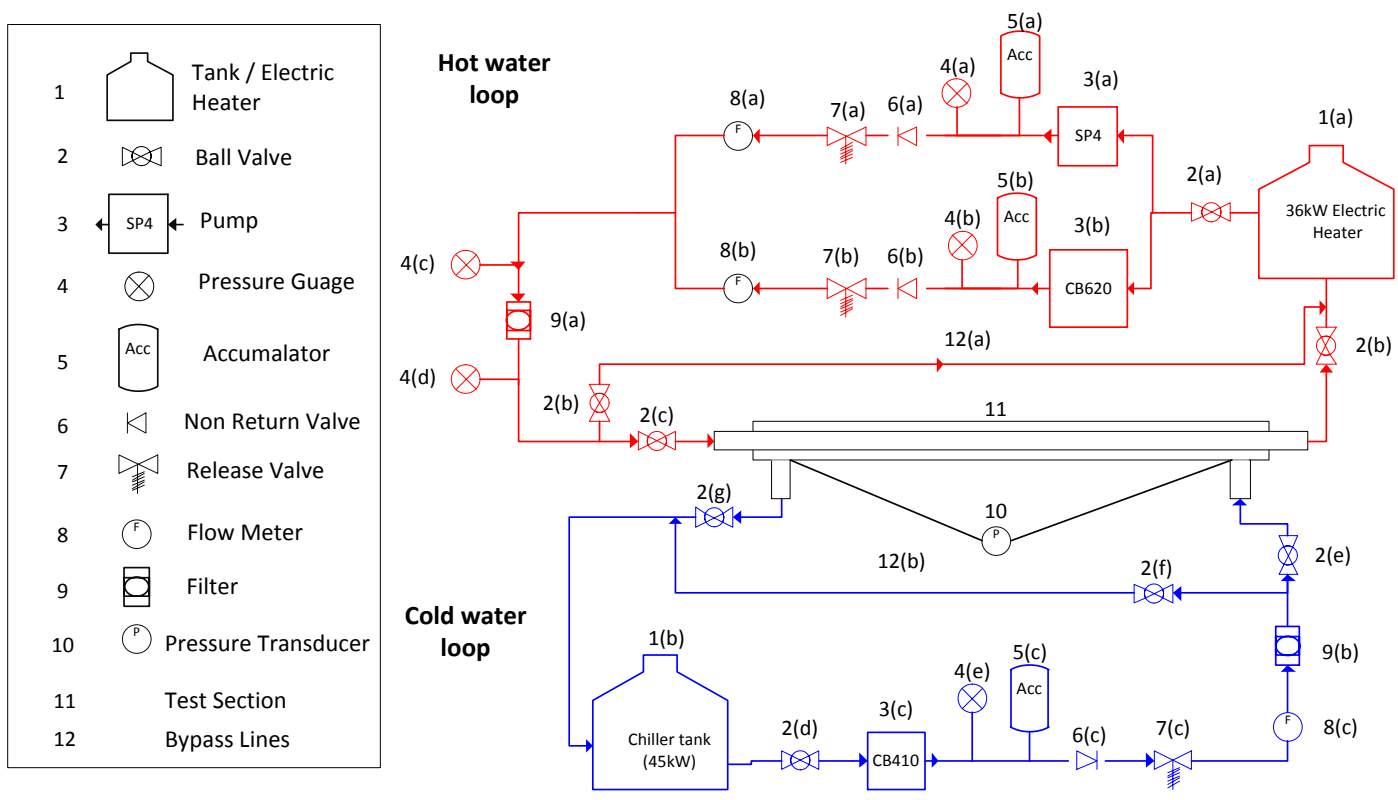

Fig.1 Diagram of the experimental test setup

The cold water loop (shown in blue) was similar to the hot water loop. It was, however, serviced instead by a $45 \mathrm{~kW}$ chiller unit connected to a 5000 litre reservoir in which the water temperature was also thermostatically regulated to within $\pm 1^{\circ} \mathrm{C}$ of the selected temperature. A positive displacement pump (item 3c) with a maximum flow rate of $5.8 \mathrm{~m}^{3} / \mathrm{h}$ was used and controlled with a variable speed drive. A $0.010 \mathrm{~m}^{3}$ accumulator (item $5 \mathrm{c}$ ) was fitted before the Coriolis flow meter (item $8 \mathrm{c}$ ), which had a range of $0-1.833 \mathrm{~kg} / \mathrm{s}$ and an accuracy of $0.1 \%$ of its full scale. This loop was also equipped with a pressure relief valve, a pressure gauge, a non-return valve, a filter and a bypass valve. Quick connectors made it relatively easy to couple the supply and return pipes of both loops onto the test section in either a cooling or heating configuration. For heating annulus cases, cold water was passed through the annulus and hot water was passed through the inner tube (see the discussion on the test section later in the article), while for cooling the opposite was true. Pressure transducers (item 10) were fitted to take-offs at the ends of the outer tube of the test section to measure the pressure drop over the length of the annulus. Pressure drop data falls beyond the scope of this article and is not included.

Data was captured using a desktop computer using equipment and software (Labview version 9.0.1) from National Instruments. Programming in Labview also enabled remote control of the speed of each 
pump. Data was recorded at a rate of $10 \mathrm{~Hz}$. The Labview interface allowed the user to get real-time feedback of current conditions in the system.

\subsection{Test Sections}

Four different annular ratio heat exchangers were used in this investigation. Each test section was constructed using hard drawn copper tubes by placing a smaller tube inside a larger tube, as is shown in Fig.2. The volume between the tubes, which constituted the annular region, had an outer wall diameter of $D_{0}$, an inner wall diameter of $D_{1}$, and a length of approximately $5 \mathrm{~m}$. The inner diameter of the inner tube had a diameter of $D_{i}$. Test sections were horizontal and had industry standard inlet and outlet ports orientated perpendicular to the axial flow direction as is shown schematically in Fig.3. The inlet and outlet ports were in the same plane and faced downwards. Pressure taps were located in each of the stagnant flow regions before and after the inlet and outlet respectively. Several temperature measuring locations were positioned along the length of both of the inner and outer tubes as will be discussed later.

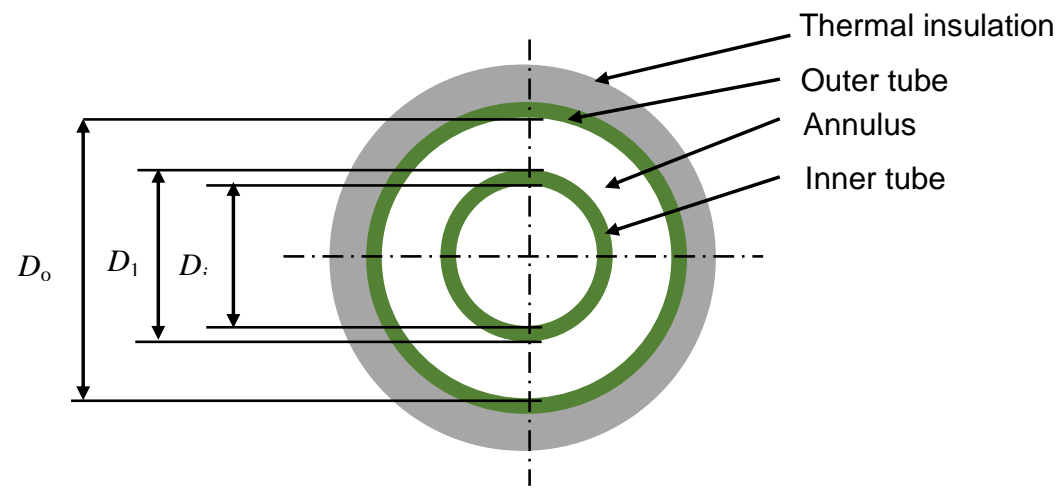

Fig.2 Cross section of heat exchanger

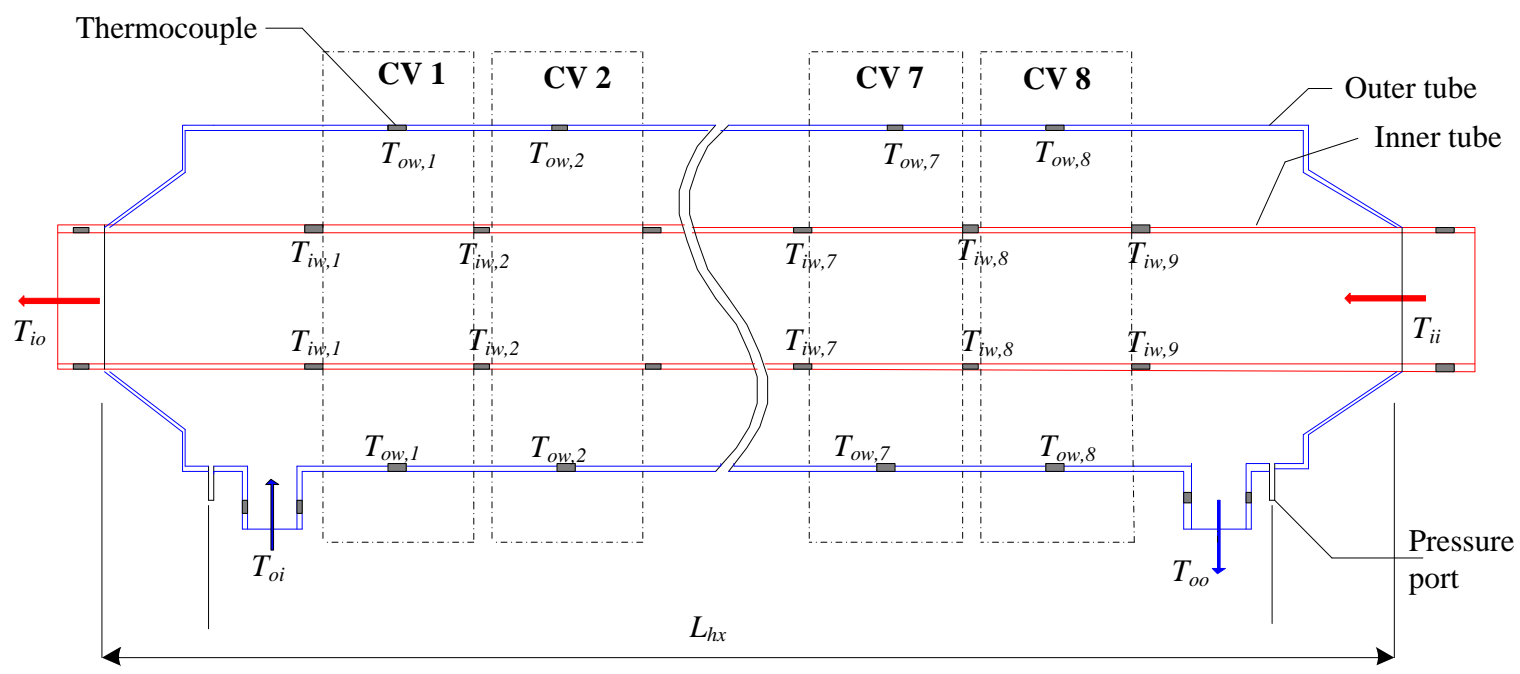

Fig.3 Axial schematic display of heat exchanger, showing inner tube, outer tube, inlets / outlets and division of control volumes (not to scale) 
Table 2 gives a summary of the dimensions of the four test sections, including the tube diameters, the resulting hydraulic diameters $\left(D_{h}=D_{0}-D_{1}\right)$ of the annuli, the resulting annular diameter ratios $(a=$ $\left.D_{1} / D_{0}\right)$, and the heat transfer lengths $\left(L_{h x}\right)$. The heat transfer length was equal to the wetted length of the inner tube, while the pressure drop length was equal to the axial distance between the inlet and outlet pressure taps.

Table 2 Summary of test section dimensions

\begin{tabular}{|l|l|l|l|l|l|l|}
\hline $\begin{array}{l}\text { Test } \\
\text { section }\end{array}$ & $\boldsymbol{D}_{\boldsymbol{i}}(\mathbf{m m})$ & $\boldsymbol{D}_{\boldsymbol{I}}(\mathbf{m m})$ & $\boldsymbol{D}_{\boldsymbol{o}}(\mathbf{m m})$ & $\boldsymbol{D}_{\boldsymbol{h}}(\mathbf{m m})$ & $\boldsymbol{a}(-)$ & $\boldsymbol{L}_{\boldsymbol{h} \boldsymbol{x}}(\mathbf{m})$ \\
\hline 1 & 14.485 & 15.900 & 32.900 & 17.000 & 0.483 & 5.10 \\
2 & 14.485 & 15.900 & 38.880 & 22.980 & 0.409 & 5.06 \\
3 & 11.180 & 12.700 & 32.900 & 20.200 & 0.386 & 5.09 \\
4 & 11.180 & 12.700 & 38.880 & 26.180 & 0.327 & 5.08 \\
\hline
\end{tabular}

Inner tube wall temperatures were measured directly at nine equally spaced measurement stations as are labelled in Fig.3 with $T_{i w}$. These local wall measurements allowed for the determination of local heat transfer coefficients using short control volumes (CVs). Each tube temperature measuring station consisted of two thermocouples spaced $180^{\circ}$ apart (one at the top of the inner tube and the other at the bottom of the inner tube).

Fig.4 illustrates the attachment of thermocouples to the inner tube. T-type thermocouples were used in this investigation. To prevent convective effects on the measured temperature due to protrusions into the annular flow, each thermocouple junction was embedded into the tube wall by placing the thermocouple tip into a milled groove $(0.46 \mathrm{~mm}$ deep and $1.2 \mathrm{~mm}$ wide). The other end was fed through a small hole drilled through the tube wall $(1.2 \mathrm{~mm}$ diameter) to allow the thermocouple leads to run inside the inner tube, inhibiting any flow obstructions in the annulus. To improve the measurement accuracy of the wall temperatures, the junction (where measurement takes place) was positioned in the groove at an annular upstream distance of $10 \mathrm{~mm}$ from the hole. This was done to separate the measurement points from the regions which could be influenced by the thermocouple wires suspended in the fluid. The junction was made by soldering the copper and constantan wires of the thermocouples leads into the groove. The remainder of the groove and hole was filled with an epoxy resin and sanded down to a smooth finish, flush with the tube's outer surface. 


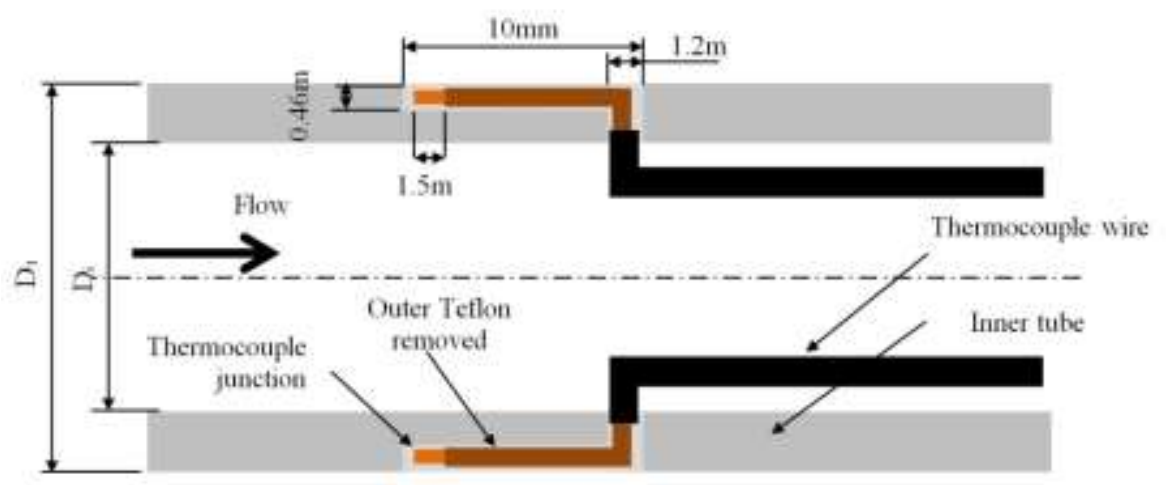

Fig.4 Attachment detail for thermocouples embedded in the inner tube wall (not to scale)

The outer tube was constructed from alternating copper sections and transparent acrylic glass sections. In total there were nine copper tube sections (with an inner diameter of $D_{0}$ and a length of $550 \mathrm{~mm}$ each) and eight acrylic glass connectors (with an inner diameter to match $D_{0}$ and an effective axial length each of $20 \mathrm{~mm}$ ). The acrylic glass connectors were used to house four hypodermic needles (diameter of $0.80 \mathrm{~mm}$ ) at $90^{\circ}$ spacing around the circumference to main a concentric positioning of the inner tube. The transparent connectors enabled inspections at a later stage to verify that the needles were still positioned correctly.

Fig.5 shows a schematic sectioned view of a connector fitted with the needles. Because the needles had a relatively small diameter compared to the hydraulic diameter, and were placed $550 \mathrm{~mm}$ apart, little obstruction to flow were induced. Thermocouples were also attached to the outer surface of the outer tube as labelled in Fig. 3 with $T_{o w}$ at intervals exactly midway between the inner tube measuring stations. Each location had two thermocouples, spaced $180^{\circ}$ apart (top and bottom of tube).

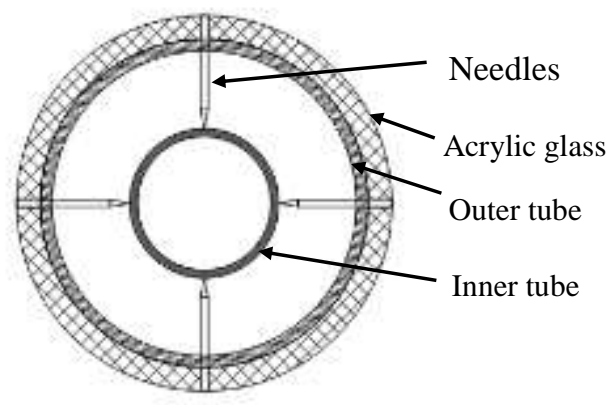

Fig.5 Diagram showing the cross section of an acrylic glass socket with needles to support the inner tube (not to scale)

Inlet and outlet bulk fluid temperatures were measured before and after the heat exchanger inlet and outlet ports respectively. For this purpose, measuring stations each with four thermocouples equally spaced around the circumference of a short copper section were used. The measuring stations were 
thermally separated from the test section by means of rubber flexible hoses and sufficiently thermal insulated from the laboratory surroundings. The use of four thermocouples at each of these stations were important to reduce the measuring uncertainty as will be described in more detail later.

The entire test section was wrapped in synthetic rubber foam insulation, with a thermal conductivity of $0.036 \mathrm{~W} / \mathrm{mK}$ and a minimum thickness of $25 \mathrm{~mm}$. This reduced heat loss to the surrounding lab to below $0.5 \%$ of the internally transfered heat in the worst cases.

\section{Experimental Procedure}

\subsection{Calibration}

Before any main tests were conducted, careful calibration of the thermocouples and pressure transducers were performed.

Thermocouples were calibrated in-situ by running a range of isothermal tests whereby the same water was circulated through the test section in the inner tube as well as the annulus at relatively high mass flow rates. Two PT100 resistance temperature detectors, each with an absolute accuracy of $0.1^{\circ} \mathrm{C}$ were used and installed in-line at the inlet and outlet of the test section to monitor the system temperature. The isothermal tests were conducted at specific temperatures covering $10^{\circ} \mathrm{C}-65^{\circ} \mathrm{C}$ by thermostatically setting either the hot water or cold water reservoirs. Once steady state conditions were reached, the PT100s gave almost the same reading, usually to within $0.03^{\circ} \mathrm{C}$. From the PT100 readings all thermocouples in the test section were calibrated. These calibrations were repeated from time to time to check if the calibration factors for each thermocouple was still correct.

\subsection{Test runs}

For each annular diameter ratio seven different annular flow rates were tested, each done in combination with five inner tube flow rates. All heat transfer tests were done with counter-flow arrangements. Since the annulus is the focus of this investigation, a wider range of flow rates in the annulus was considered covering Reynolds numbers from 15000 to 45000 at increments of 5000 . To do this, the inner tube flow rate was held constant while the annular flow rate was adjusted, covering the full spectrum, after which the inner tube flow rate was adjusted and the process repeated. Inner tube flow rates covered Reynolds numbers ranging from 20000 to 40 000, also at increments of 5 000. During each test set the inlet temperatures to the inner tube and annulus were held constant by setting the thermostat at the relevant water reservoirs in the test loop. Data was logged upon reaching steady state conditions. Acceptable steady state conditions included an inlet temperature difference of less than $0.1^{\circ} \mathrm{C}$, a change in the energy balance error of less than $0.5 \%$, and a change in the temperature difference across the inner tube as well as annulus of less than $0.1^{\circ} \mathrm{C}$, over a period of 60 
seconds. Upon reaching steady state, a data set covering 200 seconds was logged at $10 \mathrm{~Hz}$ resulting in 2000 points. This data set was later filtered to find the best consecutive 200 data points, measured by the steady state criteria described above. The smallest attainable energy balance error $(E B)$ value depended on the inlet temperatures. The closer the inner tube and annulus inlet temperatures were to each other, the more difficult it was to achieve low energy balance error values due to the influence of measuring uncertainties. An energy balance error of between $0.2 \%$ and $2 \%$ (calculated via equation 1 ) was typically achieved for all test runs.

$$
E B=\frac{\left|\dot{Q}_{o}-\bar{Q}\right|}{\bar{Q}}
$$

where

$$
\bar{Q}=\frac{\dot{Q}_{i}+\dot{Q}_{o}}{2}
$$

with $\dot{Q}_{i}$ being the heat transfer rate observed/measured from the inner tube bulk fluid properties and mass flow rate, and $\dot{Q}_{o}$ the heat transfer rate observed/measured from the annular bulk fluid properties and mass flow rate. Details on how these heat transfer rates were obtained are given in the next section.

Experiments where conducted for six different annular inlet temperature and heat transfer direction cases for each test section. Heating conditions were considered for inlet temperature of $15^{\circ} \mathrm{C}, 20^{\circ} \mathrm{C}$ and $30^{\circ} \mathrm{C}$, referred to as cases $\mathrm{H} 15, \mathrm{H} 20$ and $\mathrm{H} 30$, while cooling conditions were considered for inlet temperature of $30^{\circ} \mathrm{C}, 40^{\circ} \mathrm{C}$ and $50^{\circ} \mathrm{C}$, referred to as cases $\mathrm{C} 30, \mathrm{C} 40$ and $\mathrm{C} 50$. A summary of the test cases is given in Table 3 which resulted in 840 different test condition combinations. Due to equipment limitations it was not always feasible to achieve the exact required inlet temperature but temperatures where always maintained within $\pm 1.5^{\circ} \mathrm{C}$ of the target temperature. 
Table 3 Summary of test cases

\begin{tabular}{|l|l|l|}
\hline Variable & Test points / Range & $\begin{array}{l}\text { Number of } \\
\text { variable variations }\end{array}$ \\
\hline Annular diameter ratio, $a$ & $0.327,0.386,0.409$ and 0.483 & 4 \\
\hline $\begin{array}{l}\text { Inlet temperature } \\
\text { Heated annulus }\end{array}$ & 15,20 and $30^{\circ} \mathrm{C}($ Cases H15, H20 and H30) & 3 \\
Cooled annulus & 30,40 and $50^{\circ} \mathrm{C}($ Cases C30, C40 and C50) & 3 \\
\hline $\begin{array}{l}\text { Flow rates } \\
\operatorname{Re}_{i}\end{array}$ & $20000-40000$, increments of 5000 & 5 \\
$\operatorname{Re}_{D h}$ & $15000-45000$, increments of 5000 & 7 \\
\hline & Total Tests: & 840 \\
\hline
\end{tabular}

\section{Data reduction}

The heat transfer rate of the annular fluid is given as:

$$
\dot{Q}_{o}=\dot{m}_{o} c_{p, o}\left(\bar{T}_{o i}-\bar{T}_{o o}\right)
$$

where $\dot{m}_{o}$ is the annular mass flow rate as obtained from the mass flow meter, $c_{p, o}$ is the specific heat calculated at the average annular fluid bulk temperature by using the method of Popiel and Wojtkowiak [6], and $\bar{T}_{o i}$ and $\bar{T}_{o o}$ are the arithmetic averages of the thermocouple measurement at the inlet and outlet measuring stations respectively of the annulus. Alternatively, to increase accuracy since the temperature difference between the inner tube inlet and outlet was greater than that of the annulus, the heat transferred could also be calculated by:

$$
\dot{Q}_{i}=\dot{m}_{i} c_{p, i}\left(\bar{T}_{i i}-\bar{T}_{i o}\right)
$$

where $\dot{m}_{i}$ is the mass flow rate through the inner tube as obtained from the mass flow meter, $c_{p, i}$ is the specific heat calculated at the average inner tube fluid bulk temperature and $\bar{T}_{i i}$ and $\bar{T}_{i o}$ are the arithmetic averages of the thermocouple measurement at the inlet and outlet measuring stations respectively of the inner tube.

The average heat transfer coefficient between the inner tube and annulus can be expressed as:

$$
\bar{h}=\frac{\dot{Q}_{l}}{A_{s} \Delta T_{L M T D}}
$$


with $\dot{Q}_{\iota}$ being the heat transfer rate from the inner tube to the annulus, $A_{s}$ is the wetted surface area defined by equation (6) and $\Delta T_{L M T D}$ is the logarithmic mean temperature difference for the annulus defined by equation (7).

$$
\begin{gathered}
A_{s}=\pi L_{h x} D_{1} \\
\Delta T_{L M T D}=\frac{\left(\bar{T}_{i w}-\bar{T}_{o i}\right)-\left(\bar{T}_{i w}-\bar{T}_{o o}\right)}{\ln \left[\left(\bar{T}_{i w}-\bar{T}_{o i}\right) /\left(\bar{T}_{i w}-\bar{T}_{o o}\right)\right]}
\end{gathered}
$$

The logarithmic mean temperature difference is based in this paper on the average inner wall temperature, $\bar{T}_{i w}$ computed by summation of all relevant thermocouple measurements on the inner tube, divided by the number of thermocouples $(n)$ :

$$
\bar{T}_{i w}=\left(\sum T_{i w, j}\right) / n
$$

The use of the average inner wall temperature instead of using the extrapolated inner wall temperatures at the inlet and the outlets of the heat exchanger was selected due to the fact that in this study accurately measured inner tube temperatures were available. This should eliminate any errors due to a linear approximation of temperatures that might in fact have a non-linear scatter. The average surface temperature is used as the heat transfer coefficients to be calculated are the average values over the length of the heat exchanger test section.

The average Nusselt number is defined as:

$$
\overline{\mathrm{Nu}}_{D h}=\frac{\bar{h} D_{h}}{k}
$$

where $k$ is the thermal conductivity of the bulk fluid evaluated at the average bulk fluid temperature using the equations of Popiel and Wojtkowiak [6].

Because the local inner wall temperatures were measured, local heat transfer coefficient can also be obtained if the local bulk fluid temperature is known. A possible method for approximating the local bulk fluid temperature in the annulus is by assuming that the fluid temperature would have the same axial direction profile as the measured temperature profile of the outer wall. In order to do this, the method of least squares fitting [7] was used to fit an exponential curve through the measured outer wall temperatures points and attain a profile which was then fitted through the annulus outlet temperature to reconstruct an approximated annulus bulk fluid temperature profile. A curve fit was 
also applied to the measured inner tube wall temperatures to allow predictions of temperature at any point along the length of the tube for local analysis. By dividing the test section into shorter control volumes as shown in Fig.3, the local heat transfer coefficient could be determined by using the same method as described earlier, but by using the local inlet and outlet annulus fluid temperature and local average wall temperature for each control volume. Eight control volumes were used, each having an axial length of $550 \mathrm{~mm}$, which span the downstream distance from $0.315 \mathrm{~m}$ to $4.750 \mathrm{~m}$ from the inlet. This was based on the fact that for turbulent flow in a circular tube, the thermal entrance region is commonly approximated to be 10 times the tube's inner diameter [8]. However, for annular flow passages, there are no clear guidelines as the length of the thermal entry length. By taking the thermal entrance length to be 10 times the largest hydraulic diameter, an entrance region of $262 \mathrm{~mm}$ is obtained. Adding another $20 \%$ as safety factor resulted in a hypothetical assumption that $0.315 \mathrm{~m}$ was needed for thermally developed flow.

The annular Reynolds number is defined as:

$$
\operatorname{Re}_{D h}=\frac{\dot{m}_{o} D_{h}}{\mu_{o} A_{o}}
$$

where $A_{o}$ is the flow cross sectional area based on $D_{0}$ and $D_{1}$, and $\mu_{o}$ is the kinematic viscosity evaluated at the average bulk fluid temperature using the method of Popiel and Wojtkowiak [6].

The Nusselt number is temperature dependent due to the properties calculated at the mean bulk temperature. To investigate the difference between a heated and cooled annulus, it would be convenient to partially remove major temperature effect. This was done by considering the Colburn $j$ factor for heat transfer [8], computed as:

$$
j=\frac{\mathrm{Nu}_{D h}}{\operatorname{Re}_{D h} \operatorname{Pr}^{m}}
$$

where $\operatorname{Pr}$ is the Prandtl number computed at the mean bulk temperature using [6]. Exponent $m$ for the standard $j$-factor is $1 / 3$, but as will be shown later, other values of $m$ could also be considered.

\subsection{Uncertainties}

As mentioned, six test cases were considered defined as either being heating or cooling cases at different annular inlet temperatures (H15, H20, H30, C30, C40 and C50). An uncertainty propagation analysis was done using the method of Kline and McClintlock [9] to determine the uncertainty in the calculation of the Nusselt numbers and the $j$-factors. Each case was examined over a range of annular 
and inner tube Reynolds numbers, $\operatorname{Re}_{D h}$ and $\mathrm{Re}_{i}$. Table 4 gives the uncertainties of measuring equipment while the average uncertainties for each test section is summarized in Table 5. It was found that the calculated Nusselt number had uncertainties, ranging between $2.0 \%$ and $2.7 \%$. The $j$-factor had an average uncertainty of $7.7 \%$, with little variation between different annular diameter ratios.

Table 4 Uncertainties of measuring equipment

\begin{tabular}{|l|l|l|l|l|}
\hline Instrument & Range & Bias & Precision & Uncertainty \\
\hline $\begin{array}{l}\text { Thermocouple stations } \\
\text { Inlet / Outlet port }\end{array}$ & $\begin{array}{l}-200^{\circ} \mathrm{C}-350^{\circ} \mathrm{C} \\
\text { Inner / Outer tube wall }\end{array}$ & $\begin{array}{l}0.1^{\circ} \mathrm{C} \\
0.1^{\circ} \mathrm{C}\end{array}$ & $\begin{array}{l}0.0{ }^{\circ} \mathrm{C} \\
0.08^{\circ} \mathrm{C}\end{array}$ & $\begin{array}{l}0.10^{\circ} \mathrm{C} \\
0.12^{\circ} \mathrm{C}\end{array}$ \\
\hline $\begin{array}{l}\text { Coriolis flow meters } \\
\text { CMF025 (item 8a) }\end{array}$ & $0-0.607 \mathrm{~kg} / \mathrm{s}$ & $0.10 \%$ full scale & Flow rate dependent \\
CMF050 (item 8c) & $0-1.833 \mathrm{~kg} / \mathrm{s}$ & $0.10 \%$ full scale & Flow rate dependent \\
CMF100 (item 8b) & $0.694-5.55 \mathrm{~kg} / \mathrm{s}$ & $0.10 \%$ full scale & Flow rate dependent \\
\hline Pressure transducers & $0-14 \mathrm{kPa}$ & $0.25 \%$ full scale & $0.013 \mathrm{kPa}$ & $0.048 \mathrm{kPa}$ \\
& $0-22 \mathrm{kPa}$ & $0.25 \%$ full scale & $0.031 \mathrm{kPa}$ & $0.086 \mathrm{kPa}$ \\
& $0-55 \mathrm{kPa}$ & $0.25 \%$ full scale & $0.107 \mathrm{kPa}$ & $0.245 \mathrm{kPa}$ \\
\hline
\end{tabular}

Table 5 The average uncertainties for $\mathrm{Nu}_{D h}, j$-factor and friction factor

\begin{tabular}{|l|l|l|l|l|l|}
\hline & $\mathbf{0 . 3 2 7}$ & $\mathbf{0 . 3 8 6}$ & $\mathbf{0 . 4 0 9}$ & $\mathbf{0 . 4 8 3}$ & Average \\
\hline$D_{h}(\mathrm{~mm})$ & 17 & 22.98 & 20.2 & 26.18 & \\
\hline Nusselt Number Uncertainty & $2.0 \%$ & $2.1 \%$ & $2.2 \%$ & $2.7 \%$ & $2.3 \%$ \\
\hline$j$-factor Uncertainty & $2.4 \%$ & $2.5 \%$ & $2.6 \%$ & $3.0 \%$ & $2.6 \%$ \\
\hline
\end{tabular}

\section{Results}

\subsection{Typical axial temperature profiles}

The measured temperatures of the inner tube wall $\left(T_{i w}\right)$, outer tube wall $\left(T_{o w}\right)$ and annulus fluid inlet $\left(T_{o i}\right)$ and outlet $\left(T_{o o}\right)$ are shown in Fig.6 for case C50 with $a=0.386$ for arbitrary selected inner tube and annular Reynolds numbers of 35000 each. It can be seen that both the inner and outer annular wall temperature profiles have approximate linear trends. In this particular case the annular fluid entered at $50^{\circ} \mathrm{C}$ and the inner tube temperature started at $22.6^{\circ} \mathrm{C}$. Since this is an anular cooling case, all temperatures decreased along the axial length of the heat exchanger, measured form the inlet 
of the annulus. The curve fit and predicted bulk fluid and inner wall temperatures are also shown. Based on the gradients of the wall temperature and the annular bulk fluid temperature, it can be seen that smaller differences between the fluid and the wall temperatures occurred at the inlet of the annulus, compared to the outlet of the annulus. This behaviour was observed for all combinations of annular Reynolds numbers for the cooled annular cases. Heated cases also exhibited smaller temperature differences between the fluid and the wall at the inlet, but the gradient showed (as expected) an increase in annular bulk temperature along the test section length. The temperature uncertainties were within $0.12^{\circ} \mathrm{C}$, which was too small to effectively illustrate in Fig.6.

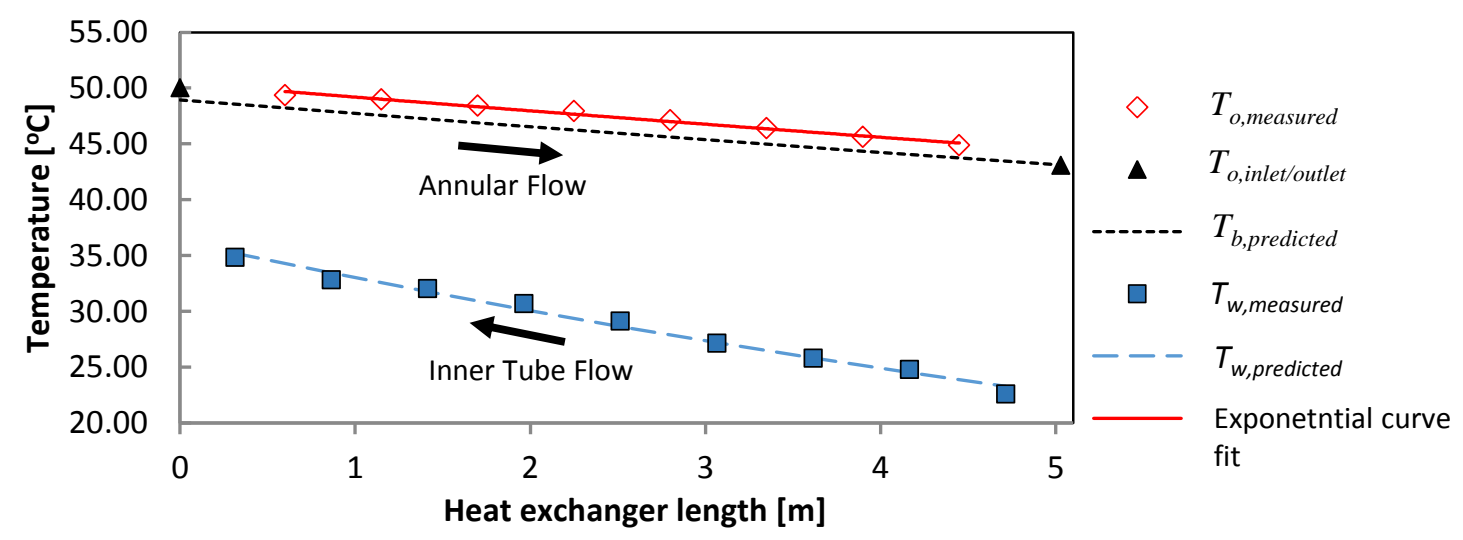

Fig.6 Measured and predicted temperatures of inner wall, annulus wall and annulus bulk fluid

\subsection{Comparison to existing correlations}

The calculated average heat transfer coefficients were compared with predictions from some of the existing correlations (as given in Table 1) using the same temperature and mass flow inputs. Refer to Fig.7 for the data of cases C50 and H15 for $a=0.386$. The correlation of Lu and Wang [5] over-predicted the experimental values, as well as the precitions of the correlations by Dirker and Meyer [2], Gnielinski [1], Swamee et al [4] and Dittus and Boelter [3], by more than 50\% and was subsequently left out. All the latter-mentioned correlations underpredicted the experimental values by between $10.3 \%$ and $28.7 \%$ depending on the flow rate and specific correlation. All of these, except for the Dittus and Boelter correlation, contained a ratio between properties dependent on the annular bulk temperature $T_{b}$ and inner tube wall temperature $T_{w i}$. The predictions of Dirker and Meyer, and Gnielinski seem to be in good correlation with the experimental data. Predictions from Dittus and Boelter appear to be better suitable for the heated case than for cooled case under consideration here. Although the correlations of Dirker and Meyer, and Gnielinski made predictions on average within $15.8 \%$ and $10.2 \%$ of the measured values, there was no single correlation that was able to consistently correctly predict the Nusselt number for both cooled and heated annuli over the considered range of $\operatorname{Re}_{D h}$ and $T_{o i}$. The predictions of Gnielinski was most accurate, varying between $9.2 \%$ (for $\mathrm{H} 20$ ) and $11.5 \%$ (for C30) from the experimental values. The predictions of Swamee et al. were also very little 
influenced by the inlet temperature and varied between $28.7 \%$ (for C50) and $32 \%$ (for C30). The relative accuracy of the Dirker and Meyer correlation did not seem to be influenced by the heat transfer direction, in contrast to predictions of Gnielinski and Dittus and Boelter which produced on average $1.4 \%$ and $7.1 \%$ better predictions for the heated cases.
- This study
$\square \quad$ Dirker \& Meyer [2]
$\triangle$ Gnielinski [1]
$\times$ Swamee et al. [4]
C Dittus \& Boelter [3]

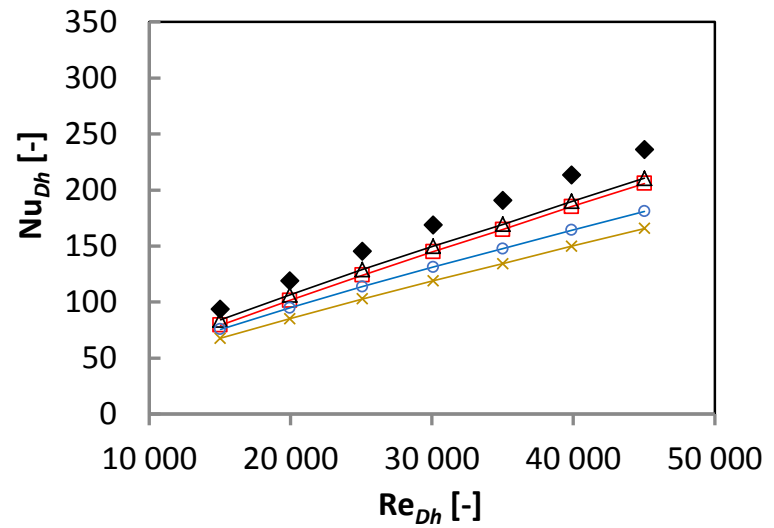

(a) Case C50

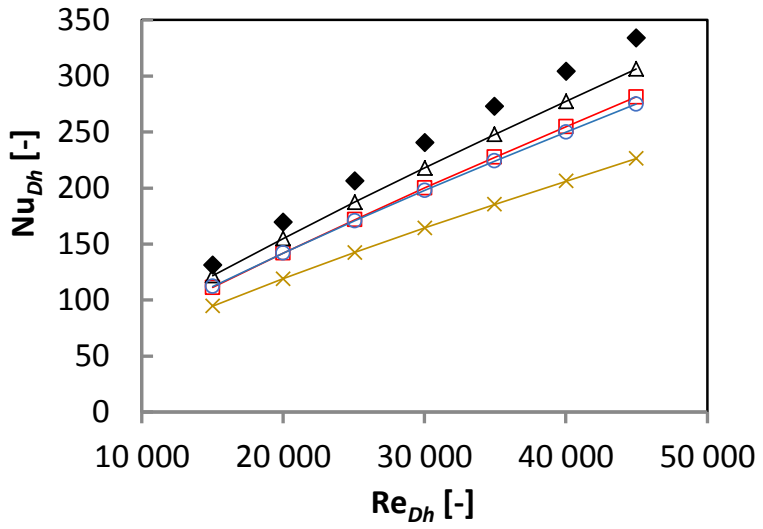

(b) Case H15

Fig.7 Comparison of computed Nusselt number and correlations with $a=0.386$ for (a) cooling of the annulus with $T_{o i}$ at $50^{\circ} \mathrm{C}$ and (b) heating with $T_{o i}$ at $15^{\circ} \mathrm{C}$

\subsection{Influence of the inlet temperature and the heat transfer direction}

Fig. 8 shows the average Nusselt numbers in terms of the annular Reynolds number for the six inlet temperature and heat transfer direction cases. Heated cases are represented with dashed lines while cooled cases are represented by solid lines. The reported results at a particular annular Reynolds number is based on the averaged results as obtained from different inner tube Reynolds number conditions. It was found that the inner tube Reynolds number had a relatively small impact on the average heat transfer coefficient. The difference in the calculated average Nusselt number for a particular annular Reynolds number varied by at most $1.2 \%$ when the inner tube Reynolds number was changed from 20000 to 40000 , and is for that reason omitted from the detailed discussion of the results. The close agreement of the results for a particular annular Reynolds number does, however, indicate that high levels of repeatability in the results were attained.

It can be noted from Fig. 8 that cases H15, H20 and H30 (all heated cases with relatively cold annular fluid temperatures) had higher Nusselt numbers compared with cases C30, C40 and C50 (all cooled cases with relatively warm annular fluid temperatures). As expected, the Nusselt numbers increased with an increase in the Reynolds number while an increase in the fluid temperature resulted in a decrease in the Nusselt numbers. For instance as can be seen in Fig. 8 (b), for $a=0.386$, case H15 on 
average had $\mathrm{Nu}_{D h}$ values $30.8 \%$ greater than case C50. Cases $\mathrm{H} 30$ and $\mathrm{C} 30$ both had annular inlet temperatures of $30^{\circ} \mathrm{C}$. For this annular diameter ratio, on average the $\mathrm{H} 30$ heated case had Nusselt numbers marginally higher by $0.28 \%$ compared to the $\mathrm{C} 30$ cooled case. Based on this, it might seems as if the heat transfer direction is not important, however, the same close agreement between cases $\mathrm{H} 30$ and C30 does not exist for the test sections with $a=0.327,409$, and 483 as is shown in Fig.8 (a), (c) and (d).

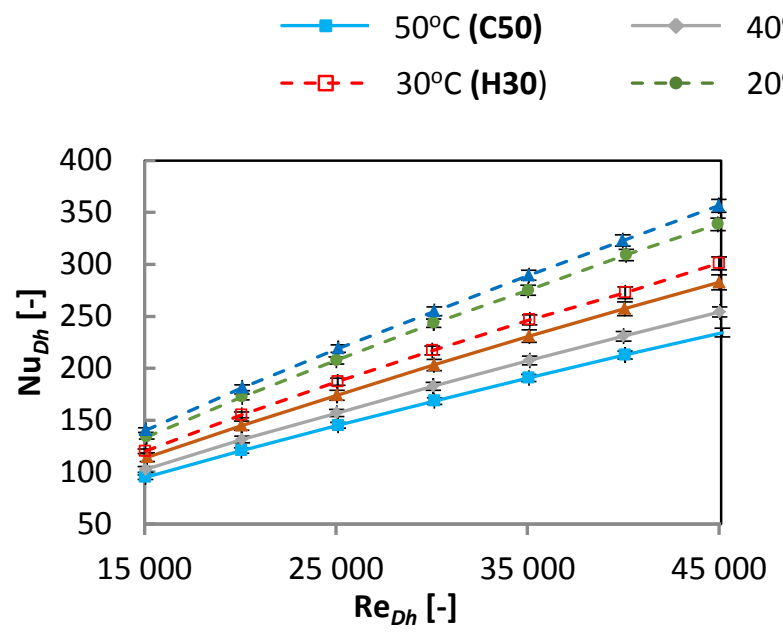

(a) $a=\mathbf{0 . 3 2 7}$

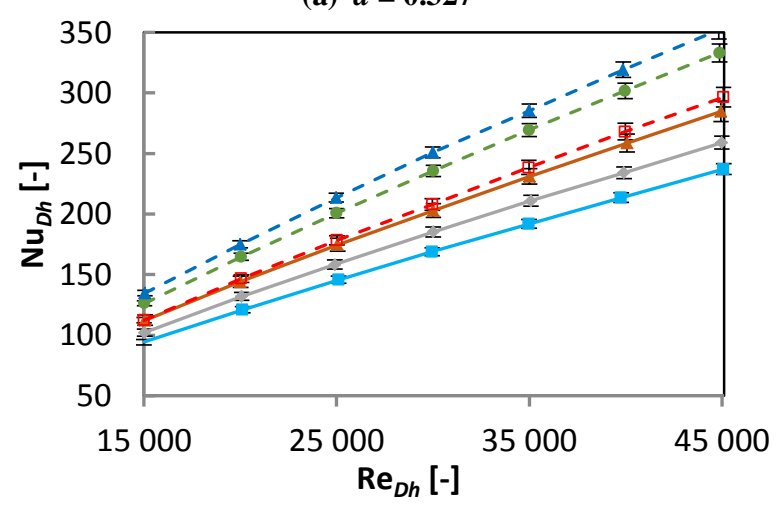

(c) $a=0.409$

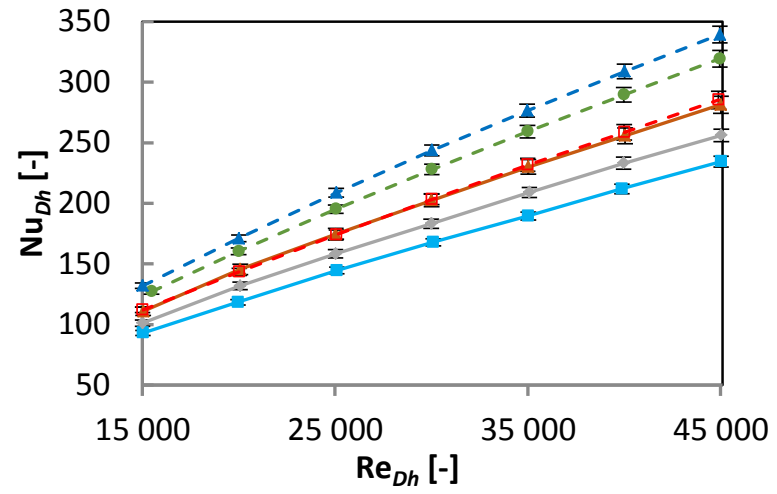

(b) $a=0.386$

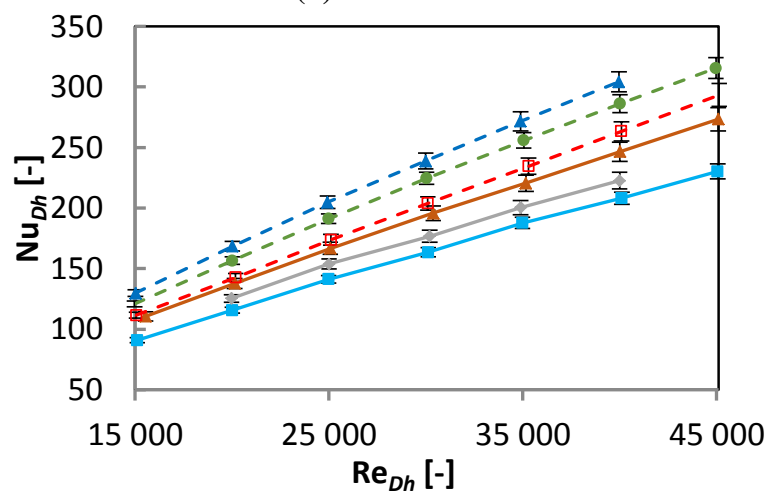

(d) $a=\mathbf{0 . 4 8 3}$

Fig.8 Nusselt numbers for the six inlet temperature cases in the different test sections

Thus even though the inlet fluid temperature plays an important role on the magnitude of the heat transfer coefficient, the heat transfer direction also has to be considered. Refer to Fig.9 which shows how, for constant annular Reynolds numbers, the Nusselt number varies with the average annular bulk temperature based on the data in this investigation (calculated for the entire length of the annulus and includes the heating or cooling influence). Data points for cases H15 through to case C50 are labelled for convenience. In general, it can be seen that as the average bulk temperature increases, the Nusselt number decreases. However, for $a=0.327,409$, and 483 there is a distinct disruption to this trend at 
approximately $30^{\circ} \mathrm{C}$ between the data points for $\mathrm{C} 30$ and $\mathrm{H} 30$. Because cases $\mathrm{H} 30$ and $\mathrm{C} 30$ had approximately the same inlet bulk fluid temperature, with different heat transfer directions (to / from the annulus), their experimental data could be used to determine what impact the heat transfer direction has on the heat transfer coefficient. Because of the cooling and heating effects, the C30 cases had lower average bulk fluid temperatures than the H30 cases. Refer to Fig.10 which, for $a=$ 0.327 , connects the heated and cooled cases with data lines. It can clearly be seen that the heated and cooled cases fall on two separate data-trends in terms of the dependence of the Nusselt number on the average bulk fluid temperature. Similar observations can easily be made for $a=409$, and 483 based on the data in Fig.9 (c) and (d). For $a=0.386$ (Fig.9 b) this is also true, but it is not as visible. Thus, from this it is clear that heated cases result in higher heat transfer coefficients, irrespective of the fluid temperature. For instance for $a=0.327$ a heat transfer coefficient of $10 \%$ or more is obtained at a Reynolds number of 45000 . This difference is significantly greater than the uncertainty of the results.

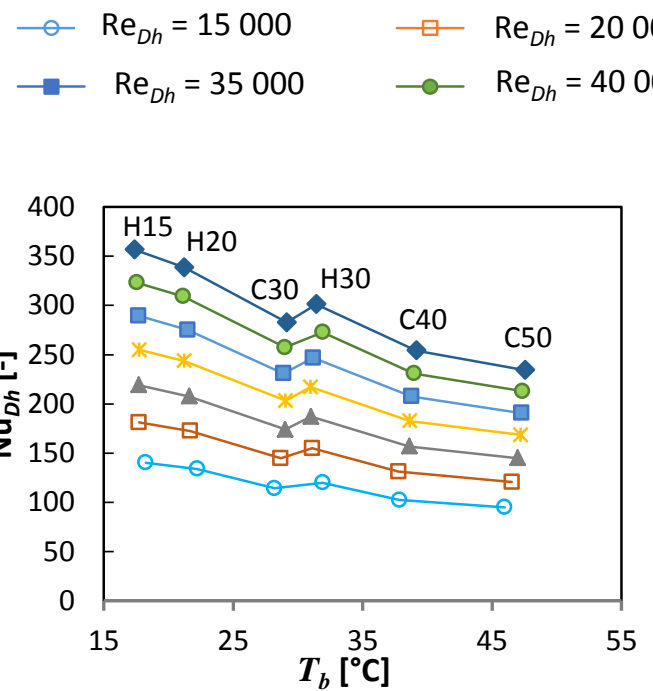

(a) $a=0.327$

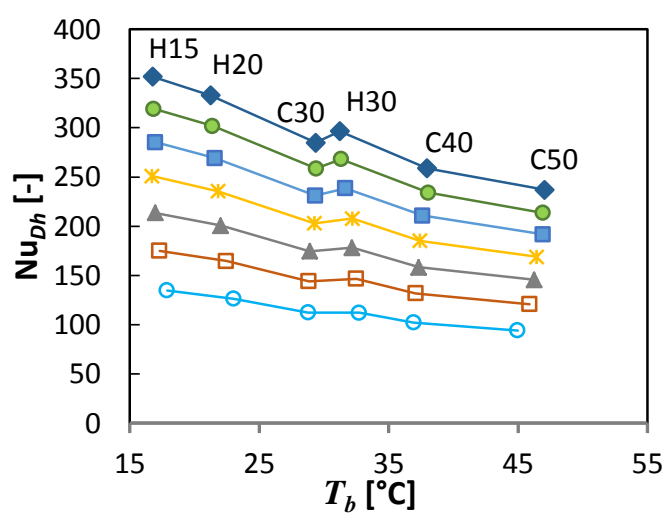

(c) $a=0.409$
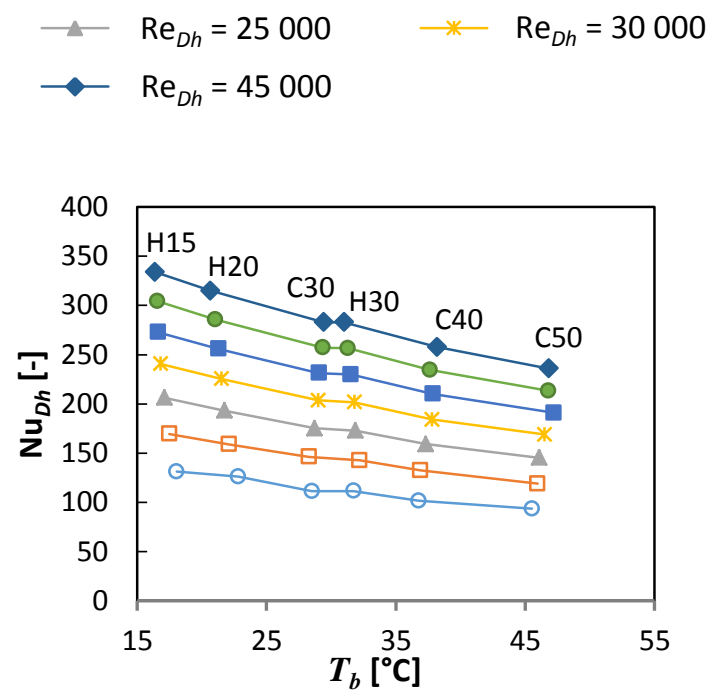

(b) $a=0.386$

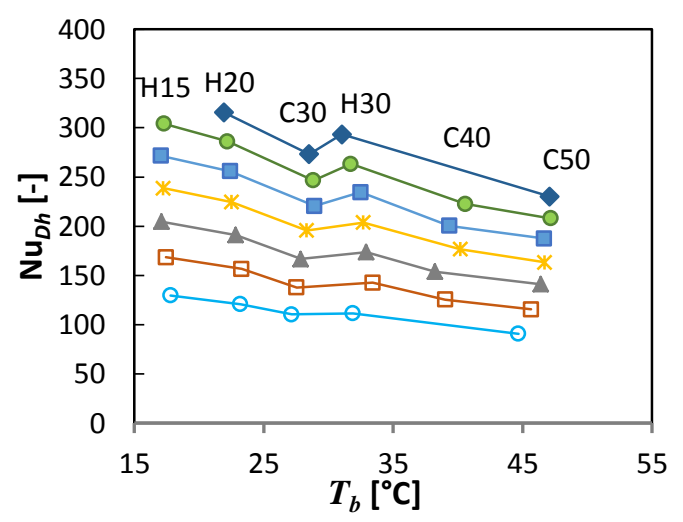

(d) $a=0.483$

Fig.9 Variation of $\mathrm{Nu}_{D h}$ in terms of the annular bulk fluid temperature at different $\mathrm{Re}_{D h}$ 


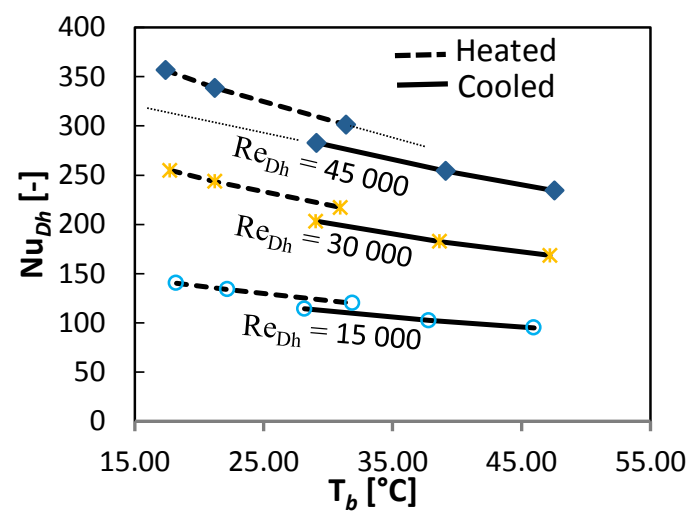

Fig.10 Heated and cooled $\mathrm{Nu}_{D h}$ values for the 0.327 test sectiFon at different $\mathrm{Re}_{D h}$ values

Results for the Colburn $j$-factor for $m=1 / 3$ is shown in Fig.11. It can be observed that the $j$-factor decreases with both an increase in the Reynolds number and an increase in the fluid inlet temperature. For $a=0.386$ for instance, the $j$-factor for case H15 was on average $13.1 \%$ higher than for case C50. For case $\mathrm{C} 30$ versus case $\mathrm{H} 30$, the heated annulus had a $j$-factor which was $2.6 \%$ higher value than the cooled case. It can also be noted that $j$-factor bands are present which tend to separate the heated and cooled cased from each other for the data that is presented in this article. Cooled cases are grouped together in the lower band, while heated cases are grouped in the upper band. 


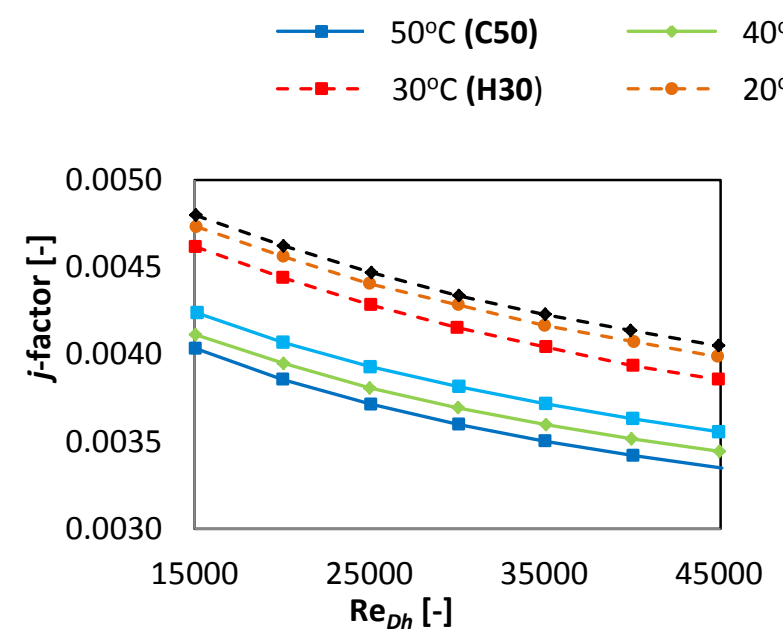

(a) $a=0.327$

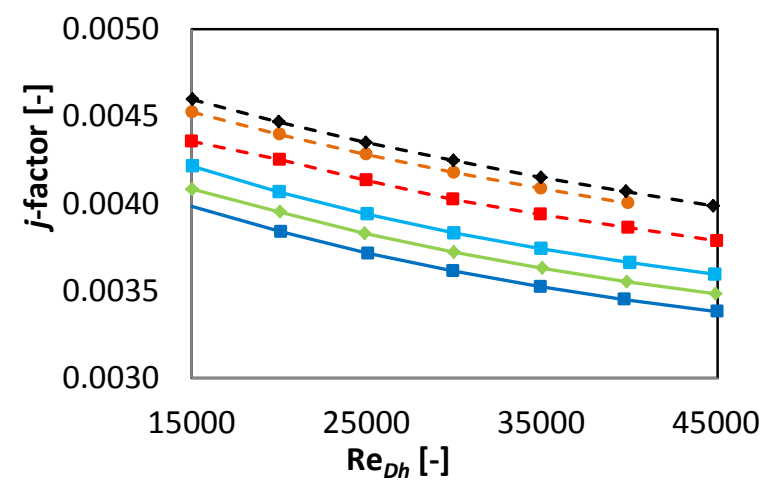

(c) $a=0.409$
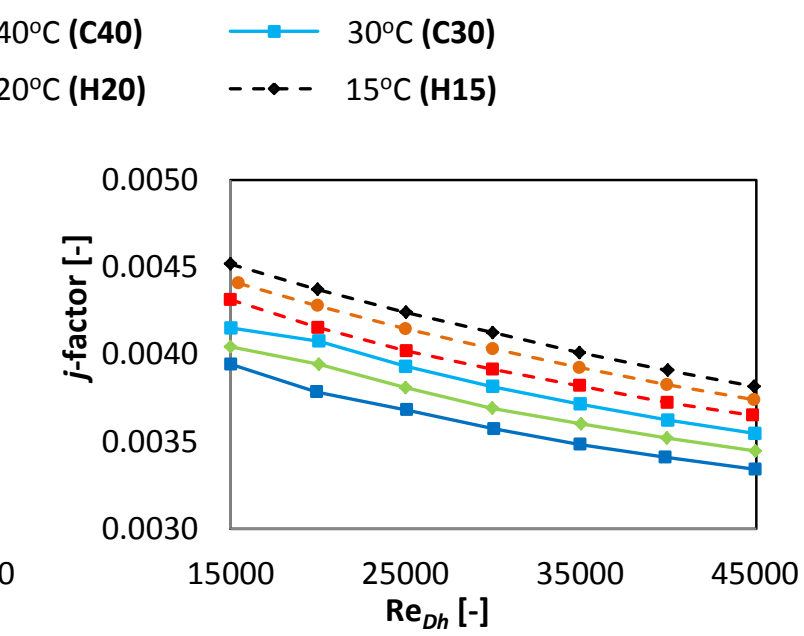

(b) $a=0.386$

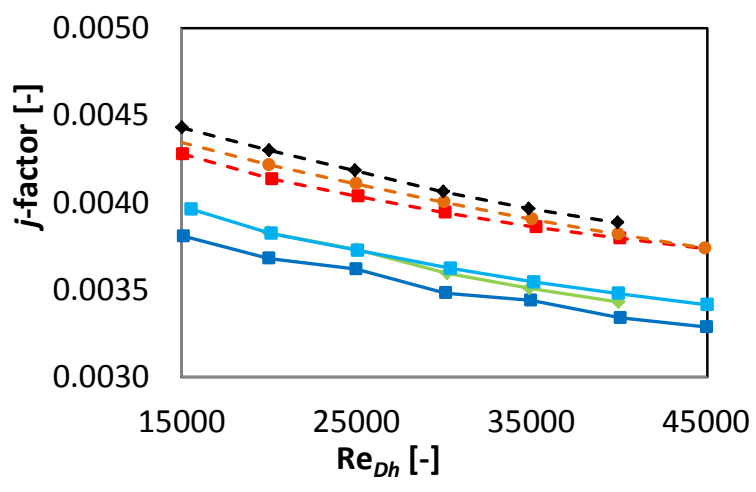

(d) $a=\mathbf{0 . 4 8 3}$

Fig.11 Colburn $j$-factors versus $\operatorname{Re}_{D h}$ for the four different annular ratios indicating the influence of heated and cooled configurations with $m=1 / 3$

Other values of the exponent $m$ can also be considered in an attempt to more effectively render the results less temperature dependent. By doing so, an adjusted $j$-factor, $j^{*}$, can be produced as is shown in Fig. 12 for an exponent value of $m=0.46$. This exponent was obtained by determining which value of $m$ resulted in the heated case data to collapse onto one line and the cooled case data to collapse on one line. From the trends in Fig.12 it is clear that for each test section heated cases are well-described by a single trend line, irrespective of the fluid inlet temperature while cooled cases are well described by a single trend line. The difference in the adjusted $j$-factors again support the idea that heated and cooled cases need to be treated differently. 


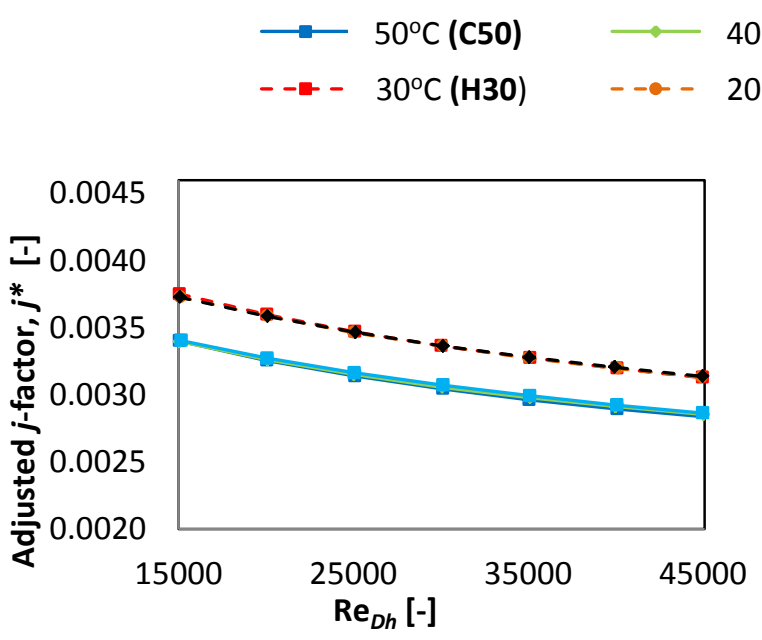

(a) $a=0.327$

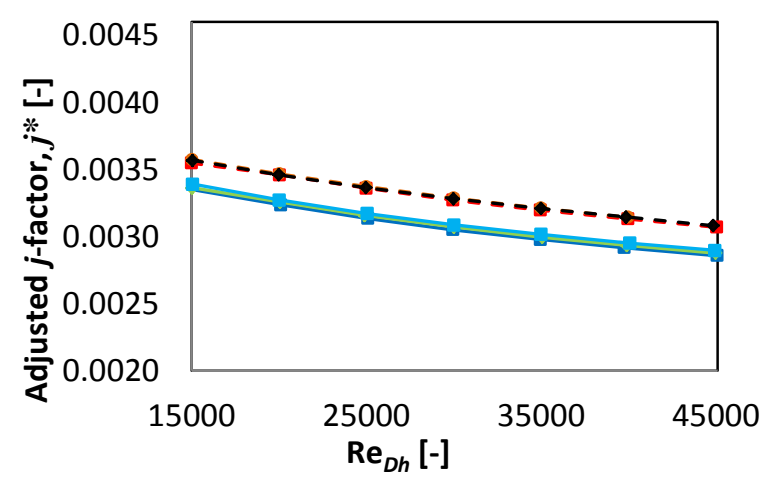

(c) $a=0.409$

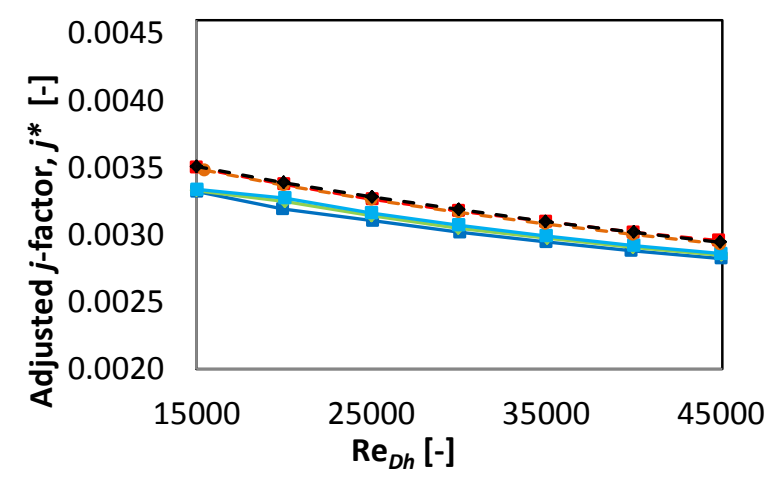

(b) $a=0.386$

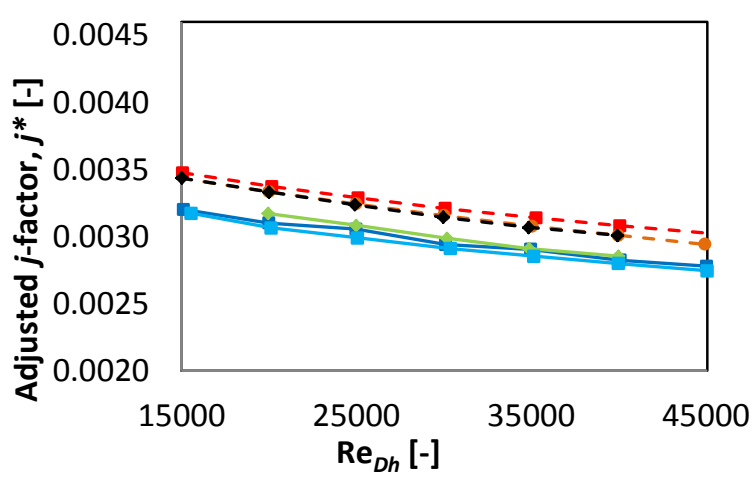

(d) $a=\mathbf{0 . 4 8 3}$

Fig.12 Adjusted Colburn $j$-factors versus $\operatorname{Re}_{D h}$ for the four different annular ratios indicating the influence of heated and cooled configurations with $m=0.46$

\subsection{Local heat transfer coefficients}

As mentioned earlier, the local heat transfer coefficients were computed by dividing the test section into equal length control volumes (CVs). By considering each control volume as a small test section, with known inlet and outlet conditions, the average Nusselt number computed for each particular control volume was estimated to be the local Nusselt number for that part of the test section. The small test sections considered resulted in high uncertainties due to the very small temperature differences, sometimes as high as $62 \%$, at the inlet, but on average the uncertainty of the local heat transfer coefficient along the length of the test section was 53\%.

Fig.13 shows the experimental local Nusselt numbers with $a=0.386$ for an arbitrary selected average annular Reynolds number of 35000 , compared to predictions of the correlations in Table 1 . The Nusselt number predictions from the correlations were obtained by applying the inlet and outlet temperature of each control volume to the correlations, in the same manner as which the local experimental Nusselt number was computed. Note that to produce Fig. 13 the mass flow rate was kept at the constant measured annular inlet value, thus resulting in a decaying Reynolds number over the 
length of the test section (each subsequent $\mathrm{CV}$ ) as a result of temperature dependent fluid properties being disregarded. The average $\mathrm{Re}_{D h}$ of 35000 was calculated using $\bar{T}_{b}$ of the entire test section. An important observation is that the calculated local experimental Nusselt numbers reduce along the length of the test section at a far higher rate than what is predicted by the correlations.

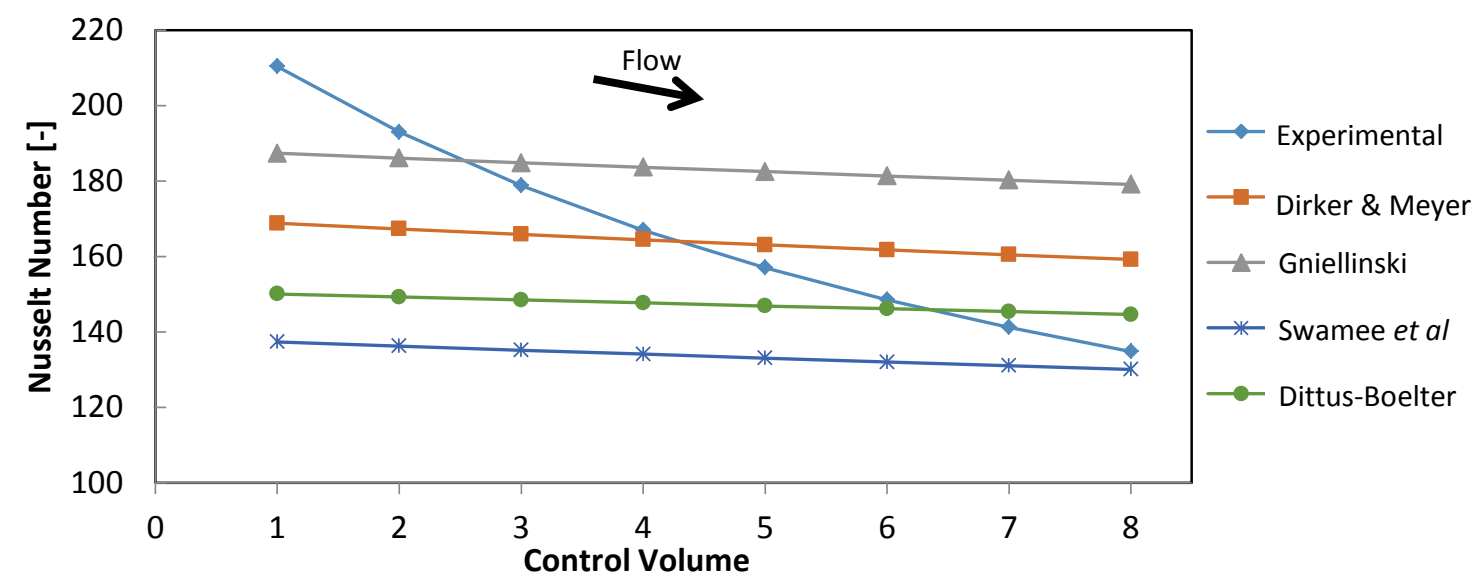

Fig.13 Comparison of calculated local heat transfer value for each $\mathrm{CV}$ of the annulus against predictions of existing correlations. ( $a$ of 0.386 , average $\operatorname{Re}_{D h}=35000, \mathrm{C50}$ )

More detailed trends are supplied in Fig.14, illustrating the local Nusselt number for $a=0.386$ at different values of constant local Reynold numbers over the control volumes for cases C50 and H15. The charts have been scaled similarly to allow visual comparison. As expected, higher mass flow rates resulted in higher local Nusselt numbers. It can be noted that for a particular Reynolds number, the calculated local Nusselt numbers at the inlet of case H15 are significantly higher than for case C50, but that towards the outlet of the annulus, similar local Nusselt numbers are present. Thus, the differences in the Nusselt numbers between cases C50 and H15 appear to be dependent on the heat transfer direction effect and is specifically susceptible to the region close to the inlet. This requires further investigation and falls beyond the scope of this article. Similar trends were observed for the other annular diameter ratios. 


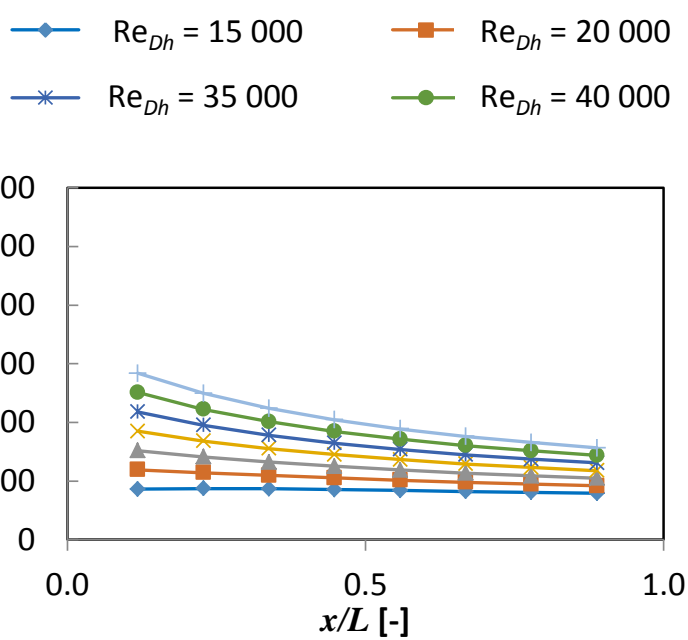

(a) Case $\mathbf{C 5 0}$
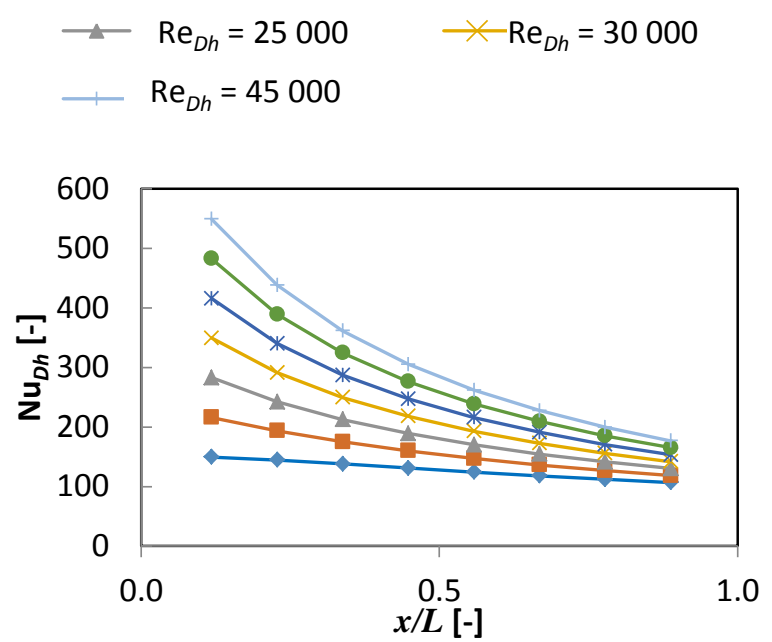

(b) Case H15

Fig.14 Local Nusselt number for $\boldsymbol{a}=\mathbf{0 . 3 8 6}$ along the length of the test section for different Reynolds numbers with inlet temperatures of (a) $50^{\circ} \mathrm{C}$ and (b) $15^{\circ} \mathrm{C}$

\subsection{Influence of the Annular Diameter Ratio}

Works by some researchers [1], [2] and [4] have suggested that the annular diameter ratio has an influence on the heat transfer coefficient and the friction factor of a test section. In this section comparisons are made among the Nusselt numbers and adjusted Colburn $j$-factors for the annular diameters considered in this article. Each of the figures in this section depicts the effect of different inlet temperature cases, Reynolds number and annular diameter ratios on the results.

The effect of the annular diameter ratio on the average Nusselt number is displayed in Fig.15 which shows the percentage difference in Nusselt number (using $a=0.327$ as reference) for all the case types. The $\mathrm{H} 20$ case for $a=0.409$ was an outlier which varied between $-11 \%$ to $-36 \%$ and was subsequently left out to make the rest of the graph more legible. It is noticed that except for the $\mathrm{H} 20$ case, there was less than $8 \%$ difference in the recorded Nusselt number over the $a$ range (average uncertainty $2.3 \%$ ). If the 0.409 section is not considered, it seems that the diameter ratio does have a small influence on the $\mathrm{Nu}_{D h}$, leading to a decrease in the Nusselt number as the annular diameter ratio increases. For heated annuli the effect is greater than for cooled annuli. 


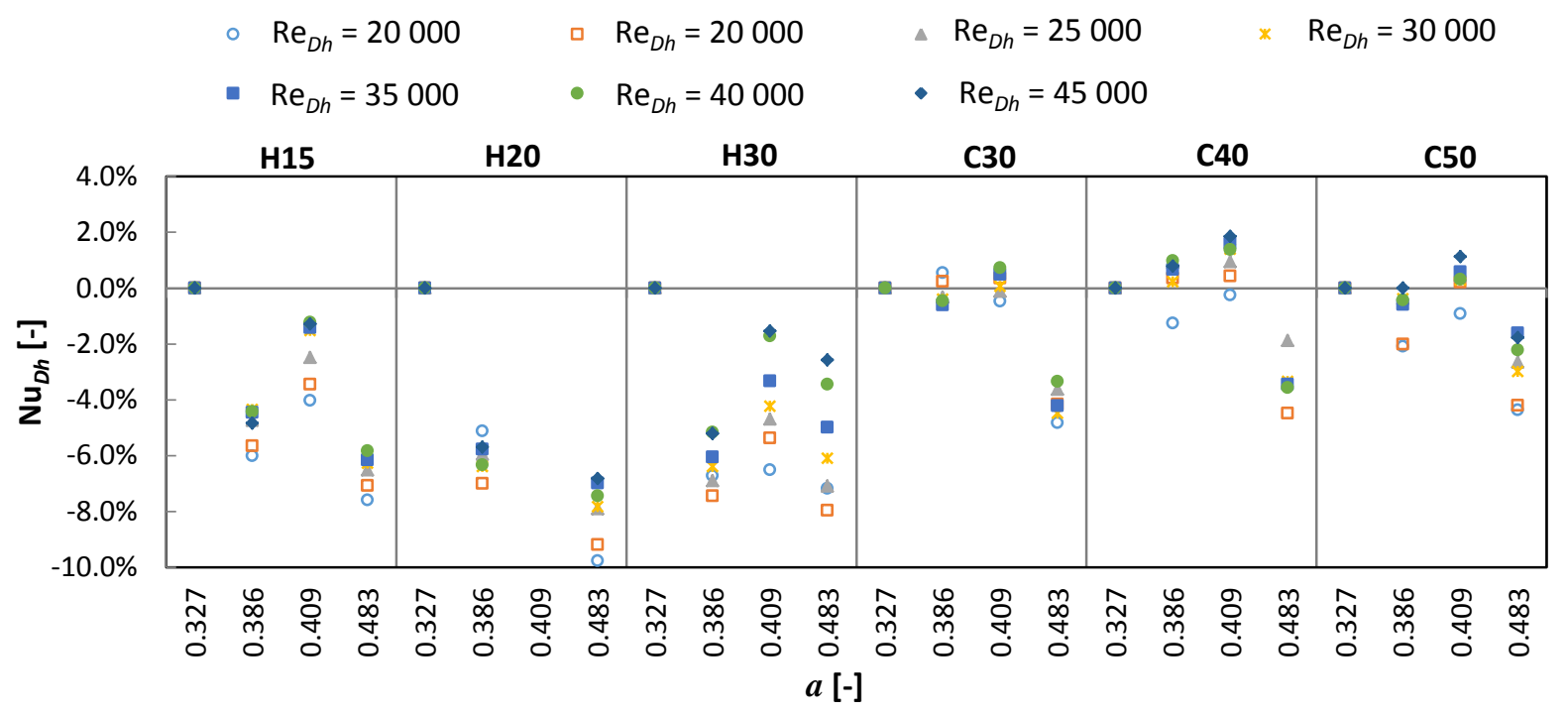

Fig.15 Nusselt number \% variation for different $\boldsymbol{a}$ compared to 0.327 value

The relative comparisons of the adjusted $j$-factors are shown in Fig.16. In general, if the $a=0.409$ results are excluded, a general downward trend in the relative $j^{*}$ values are observed as the annular diameter ratio increases. Relative magnitudes of the $j^{*}$ values, averaged over the Reynolds number data-span, are also given in Table 6. It is seen that there is a definite divide between heated and cooled cases. For the 0.327 annular diameter ratio the three heated cases differ by less than $0.2 \%$ on average, with a maximum of $9.5 \%$ higher $j *$-factor for the $\mathrm{H} 30$ case compared to the $\mathrm{C} 50$ case. On average the heated annuli has $j *$-factors of $4.9 \%, 7.1 \%$ and $7.1 \%$ consecutively for the $0.386,0.409$ and 0.483 annular diameter test sections.

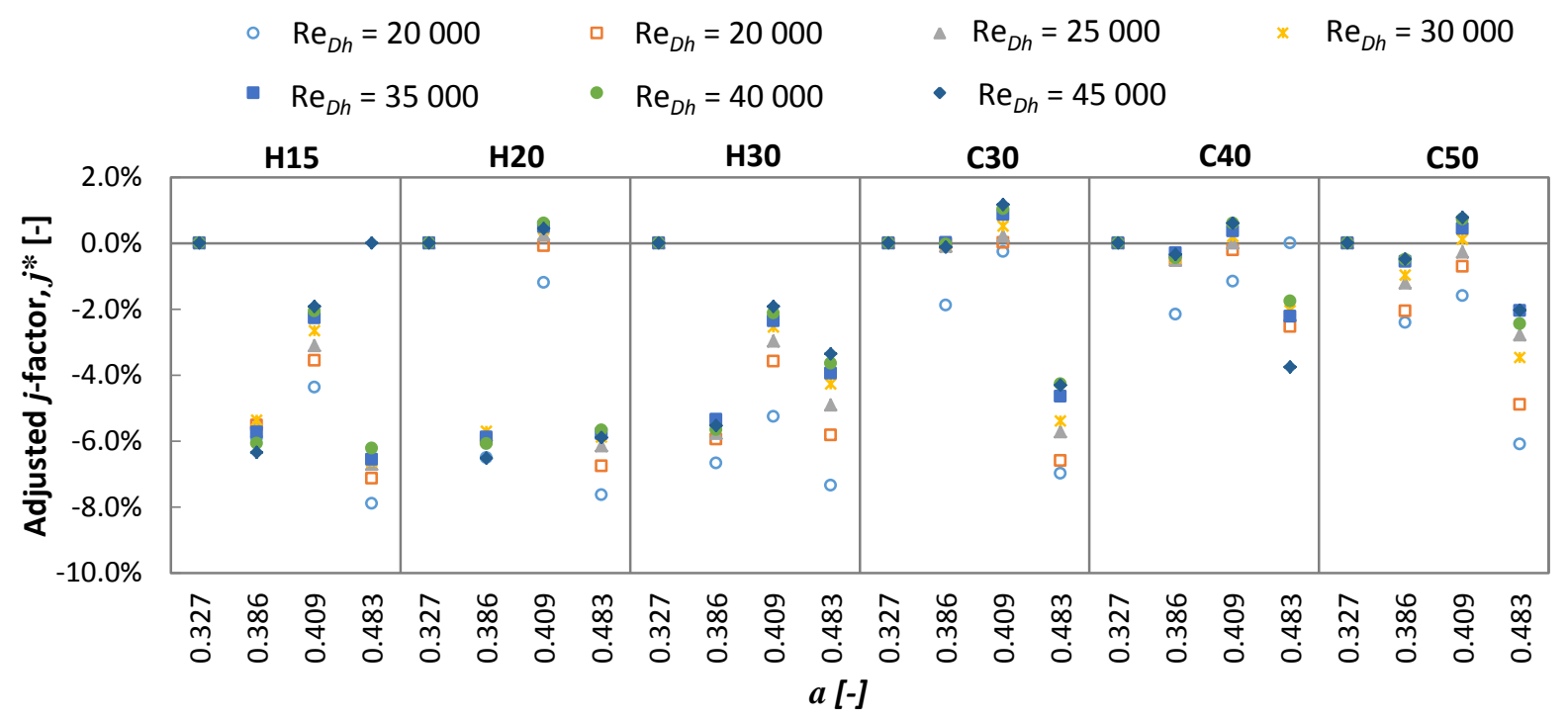

Fig.16 Adjusted Colburn $j$-factors \% variation for different $a$ compared to 0.327 value 
Table 6 Adjusted $j$-factor $(m=0.46)$ averaged over $\operatorname{Re}_{D h}$ range, given as a percentage difference from the $50^{\circ} \mathrm{C}$ inlet case, over the annular diameter ratios

\begin{tabular}{|c|c|c|c|c|}
\hline $\boldsymbol{T}_{\boldsymbol{o}}$ & $\mathbf{0 . 3 2 7}$ & $\mathbf{0 . 3 8 6}$ & $\mathbf{0 . 4 0 9}$ & $\mathbf{0 . 4 8 3}$ \\
\hline $\mathbf{5 0}^{\circ} \mathbf{C}(\mathbf{C 5 0})$ & $0.0 \%$ & $0.0 \%$ & $0.0 \%$ & $0.0 \%$ \\
\hline $\mathbf{4 0}^{\circ} \mathbf{C}(\mathbf{C 4 0})$ & $0.4 \%$ & $1.0 \%$ & $0.6 \%$ & $1.0 \%$ \\
\hline $\mathbf{3 0}^{\circ} \mathbf{C}(\mathbf{C 3 0})$ & $0.8 \%$ & $1.5 \%$ & $1.2 \%$ & $-1.3 \%$ \\
\hline $\mathbf{3 0}^{\circ} \mathbf{C}(\mathbf{H 3 0})$ & $9.5 \%$ & $4.9 \%$ & $6.5 \%$ & $7.9 \%$ \\
\hline $\mathbf{2 0}^{\circ} \mathbf{C}(\mathbf{H 2 0})$ & $9.3 \%$ & $4.5 \%$ & $8.0 \%$ & $6.3 \%$ \\
\hline $\mathbf{1 5}^{\circ} \mathbf{C}(\mathbf{H 1 5})$ & $9.4 \%$ & $5.1 \%$ & $6.9 \%$ & $7.3 \%$ \\
\hline
\end{tabular}

The adjusted $j$-factor trends in Fig.12 can be represented mathematically as follows:

$$
j^{*}=C_{o} R e_{D h}^{p}
$$

Coefficient $C_{o}$ and Reynold number exponent $p$ was found via line-fitting of the data and are given in Table 7 for each annular ratio. By employing these correlation trends, all experimental data is predicted within $1 \%$. Both the coefficient and exponent decrease as the annular diameter ratio is increased, however, a clear correlation between the annular diameter ratio and the coefficient and the exponent is not evident. Since it was found that the local heat transfer coefficient (for the boundary condition under consideration in this article) continued to decrease from the inlet towards the outlet, the annular diameter ratio on its own might not be suitable to represent the geometric impact on the averaged heat transfer coefficient. The impact of the length to diameter ratio might play an important role, but this analysis falls beyond the scope of this paper.

Table 7 Coefficients and Reynolds number exponent values for the adjusted $\boldsymbol{j}$-factor correlation trends

\begin{tabular}{|l|l|l|l|l|}
\hline \multirow{2}{*}{$\boldsymbol{a}$} & \multicolumn{2}{|l|}{ Heated annulus } & \multicolumn{2}{l|}{ Cooled annulus } \\
\cline { 2 - 5 } & $\boldsymbol{C}_{\mathbf{o}}$ & $\boldsymbol{p}$ & $\boldsymbol{C}_{\mathbf{o}}$ & $\boldsymbol{p}$ \\
\hline 0.327 & 0.0178 & -0.162 & 0.0162 & -0.162 \\
\hline 0.386 & 0.0162 & -0.158 & 0.0138 & -0.147 \\
\hline 0.409 & 0.0130 & -0.134 & 0.0137 & -0.145 \\
\hline 0.483 & 0.0126 & -0.134 & 0.0118 & -0.135 \\
\hline
\end{tabular}




\section{Conclusion}

Four heat exchangers with annular diameter ratios of $0.327,0.386,0.409$ and 0.483 were tested to experimentally obtain data regarding the dependency of the Nusselt number and $j$-factor on the annular diameter ratio, the fluid temperature and the direction of heat flux. Local Nusselt number analysis proved that the Nusselt number was higher at the entrance of the test section, reducing along the length, with the slope tending to flatten out at the exit, however classical fully-developed flow based on the heat transfer coefficient did not exist. For the data sets considered in this article, the average Nusselt number and the Colburn $j$-factor decreased somewhat with increase in annular diameter ratio. The Nusselt number and $j$-factor were greatly influenced by the fluid inlet temperature and both increased with a decrease in fluid temperature. It was found that the heat flux direction has a significant impact on the heat transfer direction. An adjusted Colburn $j$-factor was defined which clearly separates the heated case data points from the cooled case data points. Adjusted $j$-factor trends were correlated for each annular ratio.

\section{Conflicts of interest}

On behalf of all authors, the corresponding author states that there is no conflict of interest

\section{References}

1. Gnielinski, V., Heat Transfer Coefficients for Turbulent Flow in Concentric Annular Ducts. Heat Transfer Engineering, 2009. 30(6): p. 431-436.

2. Dirker, J. and J.P. Meyer, Convective Heat Transfer Coefficients in Concentric Annuli. Heat Transfer Engineering, 2005. 26(2): p. 38-44.

3. Dittus, F.W. and L.M.K. Boelter, Heat Transfer in Automobile Radiators of the Tubular Type. University of California Publications in Engineering, 1930. 2(13): p. 443-461.

4. Swamee, P.K., N. Aggarwal, and V. Aggarwal, Optimum design of double pipe heat exchanger. International Journal of Heat and Mass Transfer, 2008. 51(9-10): p. 2260-2266.

5. Lu, G. and J. Wang, Experimental investigation on heat transfer characteristics of water flow in a narrow annulus. Applied Thermal Engineering, 2008. 28(1): p. 8-13.

6. Popiel, C.O. and J. Wojtkowiak, Simple Formulas for Thermophysical Properties of Liquid Water for Heat Transfer Calculations (from $0^{\circ} \mathrm{C}$ to $150^{\circ} \mathrm{C}$ ). Heat Transfer Engineering, 1998. 19(3): p. 87-101.

7. Weisstein, E.W. Least Squares Fitting--Exponential. 6 November 2013 [cited 20133 September]; Available from: http://mathworld.wolfram.com/LeastSquaresFittingExponential.html.

8. Cengel, Y.A., Heat and Mass Transfer: A Practical Approach. 3rd ed. 2006, New York: McGraw-Hill.

9. Kline, S. and F. McClintock, Describing uncertainties in single-sample experiments. Mechanical Engineering, 1953. 75: p. 2-8. 